\title{
Learner question's correctness assessment and a guided correction method: Enhancing the user experience in an interactive online learning system
}

\author{
Saurabh Pal ${ }^{1}$, Pijush Kanti Dutta Pramanik ${ }^{\text {Corresp., } 1}$, Aranyak Maity ${ }^{2}$, Prasenjit Choudhury ${ }^{\text {Corresp. } 1}$ \\ ${ }^{1}$ Department of Computer Science \& Engineering, National Institute of Technology, Durgapur, West Bengal, India \\ 2 Department of Computer Science and Engineering, Arizona State University, Tempe, United States \\ Corresponding Authors: Pijush Kanti Dutta Pramanik, Prasenjit Choudhury \\ Email address: pijushjld@yahoo.co.in, prasenjit.chowdhury@cse.nitdgp.ac.in
}

In an interactive online learning system (OLS), it is crucial for the learners to form the questions correctly in order to be provided or recommended appropriate learning materials. The incorrect question formation may lead the OLS to be confused, resulting in providing or recommending inappropriate study materials, which, in turn, affects the learning quality and experience and learner satisfaction. In this paper, we propose a novel method to assess the correctness of the learner's question in terms of syntax and semantics. Assessing the learner's query precisely will improve the performance of the recommendation. A tri-gram language model is built, and trained and tested on corpora of 2533 and 634 questions on Java, respectively, collected from books, blogs, websites, and university exam papers. The proposed method has exhibited $92 \%$ accuracy in identifying a question as correct or incorrect. Furthermore, in case the learner's input question is not correct, we propose an additional framework to guide the learner leading to a correct question that closely matches her intended question. For recommending correct questions, soft cosine based similarity is used. The proposed framework is tested on a group of learners' real-time questions and observed to accomplish $85 \%$ accuracy. 


\section{Learner Question's Correctness Assessment and a Guided \\ 2 Correction Method: Enhancing the User Experience in an \\ 3 Interactive Online Learning System}

4

5 Saurabh Pal ${ }^{1}$, Pijush Kanti Dutta Pramanik ${ }^{1}$, Aranyak Maity ${ }^{2}$, Prasenjit Choudhury ${ }^{1}$

$6 \quad{ }^{1}$ Department of Computer Science \& Engineering, National Institute of Technology, Durgapur,

7 India

$8 \quad{ }^{2}$ Department of Computer Science \& Engineering, Arizona State University, Tempe, USA

Corresponding Authors:

Pijush Kanti Dutta Pramanik

Department of Computer Science \& Engineering

National Institute of Technology, Durgapur, India

Email: pijushjld@yahoo.co.in, pkdp15ca1503@phd.nitdgp.ac.in

Prasenjit Choudhury

Department of Computer Science \& Engineering

National Institute of Technology, Durgapur, India

20

Email: prasenjit.chowdhury@cse.nitdgp.ac.in

21 


\section{Abstract}

In an interactive online learning system (OLS), it is crucial for the learners to form the questions correctly in order to be provided or recommended appropriate learning materials. The incorrect question formation may lead the OLS to be confused, resulting in providing or recommending inappropriate study materials, which, in turn, affects the learning quality and experience and learner satisfaction. In this paper, we propose a novel method to assess the correctness of the learner's question in terms of syntax and semantics. Assessing the learner's query precisely will improve the performance of the recommendation. A tri-gram language model is built, and trained and tested on corpora of 2533 and 634 questions on Java, respectively, collected from books, blogs, websites, and university exam papers. The proposed method has exhibited $92 \%$ accuracy in identifying a question as correct or incorrect. Furthermore, in case the learner's input question is not correct, we propose an additional framework to guide the learner leading to a correct question that closely matches her intended question. For recommending correct questions, soft cosine based similarity is used. The proposed framework is tested on a group of learners' realtime questions and observed to accomplish $85 \%$ accuracy.

Keywords: n-gram; Tri-gram; Language model; soft cosine similarity; Interactive system; Elearning; Java; Word ordering error; Sequential pattern

\section{Introduction}

Online learning systems (OLSs) have brought great advantages to all kinds of formal and informal learning modes [1] [2] [3]. Over the years, OLSs have evolved from simple static information delivery systems to interactive, intelligent [4] [5], and context-aware learning systems [6], virtually incorporating real-life teaching and learning experience [7]. In today's OLSs, much of the emphasis is given on designing and delivering learner-centric learning [8] in terms of the learning style, learning approaches, and progress of a particular learner [9].

Like every learning process, one key aspect of an OLS is interaction, which makes learning more practical and dynamic [10] [11]. But, despite the advantages, due to high cost and complexity, contents developed for OLSs have limited or no interaction. The basic (or one way) interaction is incorporated in most of the OLSs through demonstration or illustration, which can be useful for very elementary learning options like remembering and comprehending. To achieve advanced learning skills like analyzing, evaluating, creating, and applying, a higher level of interactions like discussion, hands-on experiments, exchanging views with experts, etc., are required [12]. The best possible way of interaction in an OLS is to devise real-time interaction between the learner and the expert/trainer [13] [14]. In the absence of audio-video based interaction, the best option is to go for a question-answer based OLS [15] [16] since questions are the most natural and implacable way a human enquires about information.

Interacting with a computer through natural language and to make it interpret the meaning of the communicated text has many implicit challenges associated with human-computer interaction. 
Existing applications like search engines, question-answering based systems [17] [18], chatbots [19], etc., work over user queries to deliver the required information. Fundamentally, these systems process the input query to determine its structure and semantics to understand the intention of the query. Therefore, the correctness of the semantics of the query determines the response given by these automated systems.

\subsection{Significance of the Correctness of the Input Question in an Interactive Learning Systems}

For efficient information retrieval, most of the recommendation systems focus on improving the efficiency of the recommendation engine. But, how ever efficient the recommendation engine is, if the query itself is incorrect, the search engine will not be able to retrieve the suitable information that was actually intended by the user.

Similarly, in an OLS, while interacting, if the learner inputs an incorrect question, due to the absence of the cognitive ability of the search and recommendation engine of the OLS, it will try to find the learning materials against the wrong input. This will lead to inappropriate learning material recommendations, which will, in effect, dissatisfy the learner, and the purpose of the OLS will not be fulfilled. Therefore, it is important that the OLS understands the learner's actual intention when she inputs a question while interacting.

Hence, in an OLS, framing the right question in terms of grammar, word use, and semantics is an absolute requirement. But often, people frame questions incorrectly, leading to ambiguous information retrieval, which misleads learners. Generally, the following are the two reasons for an incorrect question framing:

a. Language incompetency: The lack of expertise in communicative language may cause a learner to frame a question with incorrect grammatical structure, spelling mistakes, and the inability to use appropriate words. For instance, the non-native English-speaking people having poor knowledge of English most often find it difficult to compose questions in English. For example, a question given by such a user, "HTML in how Java", demonstrates the incorrect framing of the question. What is being asked is not understandable. It could be the programming of HTML script through Java language, or it could be the application of Java program on an HTML page. The question lacks adequate articulation, due to which the desired meaning cannot be recognized. This makes correct parsing of the question impossible.

b. Lack of domain knowledge: Insufficient domain knowledge also leads to frame an incorrect question. For example, the question "how a parent class inherits a child class" is syntactically correct but semantically (or technically) incorrect. Exchanging the phrases "parent class" and "child class" would make the question correct. Ignorance or the lack of domain knowledge can reason these types of semantically incorrect framing of questions. In this case, the question might be parsed successfully, but the learner will get unintended 
results.

111 In both cases, users will not get the desired answer to their questions. Therefore, it is important to

112 validate the correctness of the question in an interactive and question-answer based automated

113 learning system.

114

115

116

117

118

119

120

121

122

123

124

125

126

127

128

129

130

131

132

133

134

135

136

137

138

139

140

141

142

143

144

\subsection{Research Objective}

From the above discussion, we can put forward the following research objectives:

- How to assess if the learner's question given as input to a query-based learning system is syntactically and semantically correct or not?

- If the question is not correct, then how to handle this to improve the recommendation?

\subsection{Existing Solution Techniques, their Limitations, and Research Motivation}

In this section, we shall investigate whether the existing methods are capable of addressing the above-mentioned research objectives.

\subsubsection{Assessing the Correctness of a Question}

The problem of assessing the correctness of a question can be described in terms of sentence validation and meaning extraction. To address the problem of validation and semantics, the following existing techniques can be used.

NLP: Progression in natural language processing (NLP) has led to advanced techniques that allow knowing sentence structure, but comprehending its semantics still remains a challenge. NLP processing techniques for determining the intention or semantics of a sentence include sentence parsing, phrase, and relevant words (or key terms) identification. The words thus identified are being related by the relationships like dependency, modifier, subject and object, action for inducing the meaning of the sentence. In determining the relationships among the words in a sentence, often rule-based approach is adopted. Defining the rules which understand words and the relationship and interdependency among them is a non-trivial task with limited application scope. Because it is not possible to rule in the usage and relationship of all words from the English language [20] [21]. And hence, understanding which word combination in framing a question is correct or incorrect is very difficult. The NLP techniques assume the placement and occurrence of words in question are implicitly correct. There is no knowledge for the words that are placed incorrectly or are missing. Unable to comprehend this, the reasons why NLP fails to identify the question framing is correct or incorrect [22] [23].

Pattern matching: In another approach, pattern matching is used to assess the correctness of the sentence. Pattern matching, in contrast to NLP techniques, is a feasible solution that allows matching a sentence pattern from available sentence patterns to find whether the sentence is matching to existing patterns or not. This approach could suitably be applied to find whether the given question is correct or incorrect. Thus, escaping the intrinsic complexity of knowledge 
145

146

147

148

149

150

151

152

153

154

155

156

157

158

159

160

161

162

163

164

165

166

167

168

169

170

171

172

173

174

175

176

177

178

mapping, word by word relationship and missing word problem as found in NLP techniques. In regard to pattern matching, the application of machine learning is very successful in following up with patterns. But, its inherent limitation in learning by not considering word sequence in a sentence had put constraints in verifying a question's rightness [21]. For machine learning algorithm, a question "can object be a data member of a class" and "can class be data member of an object" are same. The placement of words or the sequence of words in the sentence does not matter, but only their appearance matters. So, seemingly to a machine learning algorithm, both the sentences are the same [24]. This raises issues where machine learning fails to interpret sentences that are meaningfully incorrect due to misplacements of words.

\subsubsection{Addressing the Incorrect Question}

Generally, in interactive systems such as recommended systems and intelligent search engines, if the user enters an incorrect query, the system can autocorrect the wrong input query and searches information against the autocorrected query. Here, the user's involvement is not required. But this approach suffers from the following issues [25]:

- It is limited to structure and syntactic corrections of the sentence.

- Not able to correct the semantic errors.

- The intention of the query is not judged; hence, the correctness of the query may not be exact or appropriate.

\subsubsection{Motivation}

From the above discussions, it is obvious that the existing approaches have significant limitations in addressing our research goals. Moreover, none of the work has addressed the case of learner query in an OLS, i.e., the solution approaches discussed in Section 1.3.1 and 1.3.2 are neither implemented to check the correctness of a learner's incorrect question submitted to an OLS nor to resolve the issue if the input question is incorrect.

\subsection{Proposed Solution Approach}

Considering the research gap, we propose the following two ways to address the two research objectives mentioned in Section 1.2:

- Using a tri-gram based pattern matching to check the sentential (by construction) and semantical (meaning) structure of the question.

- Instead of autocorrecting, guiding the learner to the intended correct question through one or more turns of question suggestions.

The abstract layout of the proposed approach is shown in Fig. 1.

\subsection{Authors' Contribution}

To attain the above-mentioned proposals, in this paper, we made the following contributions: 
202

203

204

205

206

207

208

209

210

211

212

213

214

a) To assess the correctness of the learners' questions:

- We built two sets of corpora comprising 2533 (for training) and 634 (for testing) questions on core Java.

- We generated a tri-gram model language.

- We created a classifier to identify the correct and incorrect questions based on the tri-gram model language.

- The classification is evaluated on the test corpus data.

- The efficacy of the classifier was compared with other n-gram models as well as with other research works.

b) To address the issue of incorrect question:

- We proposed a framework for suggesting correct questions to the learner.

- We designed a web-based client/server model to implement the framework.

- The efficacy of the framework is assessed by a group of learners.

- The proposed similarity model used in the framework is compared with other existing similarity measures.

- The performance of the framework is assessed by Shannon's diversity and equitability indices.

\subsection{Paper Organization}

Section 2 mentions related work discussing the different error-checking methods and their limitation. Section 3 presents the correctness assessment methodology of the learners' questions. Guiding the learner to find the correct question is presented in Section 4. The experiments and the result analysis of both the proposed methods are discussed separately in their respective sections. Section 5 concludes the paper.

Figure 1. The layout of the proposed work and the implementational environment

\section{Related Work}

Identifying the correctness of a question is related to determining the errors in the sentential text. Sentential errors are not limited to the semantics of the text but to other different types of errors like the wrong usage of words, spelling mistakes, punctuation marks, grammatical errors, etc. Madhavi et al. [21] categorized the errors in a sentence as:

- Sentence structure error: The error in a sentence generates due to different organizations of POS components in a sentence.

- Spelling error: The error which is generated due to the wrong spelling of words or meaningless strings in a sentence.

- Syntax error: The error in sentence due to wrong/violation of grammar. The syntax error 
215

216

217

218

219

220

221

222

223

224

225

226

227

228

229

230

231

232

233

234

235

236

237

238

239

240

241

242

243

244

245

246

247

248

249

250

251

is of the following types:

○ Subject-verb error

- Article or determiner error

- Noun number error

○ Verb tense or verb form error

- Preposition error

- Punctuation error: The error in a sentence, which is generated due to misplacing or missing punctuation marks.

- Semantic error: The error that makes the sentence senseless or meaningless due to the wrong choice of words and their placing.

Among these five error types, detecting sentence structure error, syntax error, and semantic errors are the significant ones for finding the correctness of a question sentence used in a querybased interactive online recommendation system. Different approaches and strategies are found in the literature for detecting the different types of errors in a textual sentence. These different error detection approaches can be categorized as a rule-based approach, statistical approach, and hybrid approach [21]. These different error detection categories that are adopted in some notable research work that has been carried out for detecting the significant errors in a textual sentence are shown in Table 1.

Table 1. Related work categorization based on error type and resolving approach

It is seen that the rule-based approach has been quite effective in detecting sentence structure error, syntax error, and punctuation error. While, the statistical approach works well to find the structure errors, spelling errors, and semantic errors (word usage and placement error). Most of the research works for detecting an error in a textual sentence are limited to word ordering error, wrong usage of words, word collocation errors, and grammatical errors in a sentence.

The sentence structure errors due to the disarrangement of words (misplaced words) and incorrect organization of the sentence's POS components have been mitigated differently. A rulebased approach was used by Malik et al. [26] by applying POS identification and NLP production rule to check the grammatical error in the sentence. Chang et al. [27] proposed a rulebased database approach to detect word error, word disorder error, and missing word error. Similarly, Lee et al. [28] manually created a list of 60 rules to detect sentence structure errors. In another approach, Tezcean et al. [29] proposed a rule-based dependency parser that queries a treebank for detecting sentence structure error. In the statistical approach, n-gram based [30] and machine learning based [31] techniques are followed to determine the errors. Islam et al. [32] proposed sequence to sequence learning model which uses encoder-decoder architecture for resolving missing word error and incorrect arrangement of words in the sentence. The decoder is 
252

253

254

255

256

257

258

259

260

261

262

263

264

265

266

267

268

269

270

271

272

273

274

275

276

277

278

279

280

281

282

283

284

285

286

287

288

289

290

a recurrent neural network (RNN) along with long and short-term memory (LSTM) for decoding the correct substitute for grammatical errors. Sun et al. [33] followed a hybrid approach to resolve the sentence structure error. They used an NLP-based POS tagging and parse tree to determine the features of an incorrect sentence and then classified for grammatical error using the classifiers like support vector machine (SVM) and Naïve Bayes (NB).

The syntax errors are due to wrong or inappropriate use of language grammar. Over the years, different approaches (e.g., rule-based, statistical, and hybrid) have been explored in research works. For syntax error detection, rule-based techniques like the NLP production rule [26], rulebased database approach [27], and rule-based dependency parser [29] have been found to be applied. Othman et al. [34] proposed a model based on a set of Arabic grammatical rules and regular expressions. Among the different statistical techniques, the use of neural networks was found very effective in determining syntax error [35]. Different advanced variations of a neural network like bi-directional RNN with bidirectional LSTM [36] [37], neural sequence to sequence model with encoder and decoder [38], etc., are proposed for error detection in a sentence. Sonawane et al. [39] introduced a multilayer convolution encoder-decoder model for detecting and correcting syntactical errors. Besides neural networks, another machine learning technique like SVM [40] is also found to be used for detecting syntax errors. The features that are considered for learning by various machine learning approaches are prefix, suffix, stem, and POS of each individual token [41]. The error detection and correction are often carried out at the individual token level of each sentence [42]. Besides the rule and statistical-based approach, hybrid approaches are also followed for syntax error detection, thereby taking the advantages of both approaches. Kao et al. [43] used NLP and statistical methods to detect collocation errors. Sentences were parsed to find the dependency and POS of every word in the sentence. Subsequently, the collocation was matched through a collocation database to find errors. Similarly, Lee et al. [44] applied rule-based and n-gram based techniques for judging the correctness of a Chinese sentence. A total of 142 expert-made rules were used to check the potential rule violation in the sentence, while the n-gram method determines the correctness of the sentence.

The semantic error detection has largely carried out by statistical approach using techniques like n-gram methods or machine learning. The use of RNN is quite popular in semantic error detection [45]. Zheng et al. [46] and Yeh et al. [47] used an LSTM-based RNN to detect errors like redundant words, missing words, bad word selection, and disordered words. While, Cheng et al. [48] proposed conditional random fields (CRF) models to detect word ordering error (WOE) in textual segments. Zan et al. [49] proposed syntactic and semantic error detection in the Chinese language by using BERT, BiLSTM, and CRF in sequence. Similarly, Agarwal et al. [50] applied LSTM neural network architecture to make an error detection classifier for detecting two types of error - syntax and semantic error like repeated word error, subject-verb agreement, word ordering, and missing verb are identified. For detecting a grammatical error with a long sentence, Rei et al. [51] proposed a neural sequence labeling framework. The authors found bi-directional 
291 LSTM outperforms other neural network architecture like convolution and bidirectional

292

293

294

295

296

297

298

299

300

301

302

303

304

305

306

307

308

309

310

311

312

313

314

315

316

317

318

319

320

321

322

323

324

325

326

327

328

329 recurrent. Shiue et al. [52] claimed that among the other classifier, the decision tree yields better performance for morphological error and usage error. Yu et al. [53] proposed an SVM model for error detection like an adverb, verb, subject, object ordering and usage error, prepositional phase error, and pronoun and adjective ordering error. In [54], it is found that supervised ensemble classifier - Random Feature space using POS tri-gram probability offers better performance for semantic error detection in comparison to other supervised classifiers. Ferraro et al. [55] saw the different grammatical errors like sentence structure, syntax, and semantic errors as collocation errors. A collocation match in a corpus would able to detect collocation errors. Besides machine learning models, a statistical model based on sequential word pattern mining has been quite effective in detecting grammatical errors [30]. Statistical modeling and machine learning, though easy to implement, are sometimes outperformed by rule-based techniques. In [56] [33], it is found that rule-based techniques for detecting grammatical errors yield a better result for the Chinese language.

The choice of error detection technique depends much upon the rules and science of the text language under consideration. Error detection using rule-based techniques demands human expertise in framing the rules. A language with a plethora of possibilities for sentence making leads to difficulty in framing rules to capture the different types of error. Moreover, this technique can be specific to a domain or application context and cannot be generalized.

Unlike rule-based techniques, error detection using machine learning demands a huge dataset, which may not be available for all types of application scenarios. Recently, it is found that most of the syntax and semantic error detection in the text is carried by LSTM, RNN, Sequence to Sequence modeling techniques. But these techniques require corpus with incorrect and their corresponding correct sentence data with appropriate annotation or labeling. The creation of such corpus is a non-trivial task. Moreover, the models do not generalize well. This means if a sentence in the corpus is not large enough, the source sentence for error detection may appear strange to the model. Even though a lot of work has been done in error detection in the Chinese language, but there is a huge lacking of work for semantic error detection for the English language.

Various works have been done for detecting the sentence structure, syntactical and semantic errors in a sentence, but none have been found for assessing the correctness of question framing. Questions are actually textual sentences, but the way they are interpreted in comparison to the other textual sentences requires a different approach for error checking. Comprehending a question generally requires knowing "what is being asked", "which key concepts are involved," and "how the key concepts are related in context to the question". Thus, identifying the error in question framing involves issues like identifying specific ordering of the semantic words (key concepts) and identifying the verbs. The verbs and other grammatical words which relate to the key concepts orchestrate the meaning of the question. Detecting these two is important in interpreting the meaning of the question and subsequently assessing the error or wrong question

Peer] Comput. Sci. reviewing PDF | (CS-2020:10:54966:2:0:NEW 9 Apr 2021) 
330

331

332

333

334

335

336

337

338

339

340

341

342

343

344

345

346

347

348

349

350

351

352

353

354

355

356

357

358

359

360

361

362

363

364

365

framing. The characteristic features which differentiate the error checking strategy of questions from other textual sentences are given in Table 2.

\section{Table 2. Differentiating characteristic feature of question in relation to textual sentence}

Finding or detecting an error in question leads to two possibilities for correction - a) automatic error correction and b) recommending correct question. The automatic error correction techniques have not reached their maturity yet. It fails to correct sentences that are complex (logical or conceptual), and furthermore, it cannot align with the intent of the learner. Mostly the automatic error correction fails to correct semantic errors.

The other possibility is recommending the correct question, i.e., suggesting the probable correct questions to the learner against the incorrect input question. This facilitates the learner to navigate through the suggested question to choose the correct question which matches her intended question.

Most of the works on question recommendation are limited to Community Question Answer (CQA), which basically recommends the unanswered question to the user to be answered correctly [57]. The question recommendation is made based on the learner's dynamic interest [58], previous interest [59], expertise [58] [60], load [60], user model. Besides the CQA system, the question recommendation is commonly used in a frequently asked question (FAQ) based system, where questions similar or related to user questions are retrieved and recommended from the base. For finding similar questions, cosine similarity [61], syntactic similarity [62], concept similarity [62], and TFIDF, knowledge-based, Latent Dirichllet Allocation (LDA) [63], recurrent and convolution model [64] are commonly used. Despite our best effort, we did not find work on the correct question recommendation for a given incorrect question.

The only work which is close to our framework is the work done by Giffle et al. [65]. It is a question answering system developed with much focus given on the completeness of the user input question. Mostly factoid-based questions like "wh" questions and true or false questions are accepted in the system. Every time a user inputs a question, it is lexically and syntactically analyzed to find the named entities - what is being asked and what is the subject of the question. The input question strength is calculated as a score based on its completeness. If the score is high, suitable answers are recommended from the base. When the score is less than a threshold, the user is given feedback on restructuring the question, and the entire process cycle is repeated until the input score is high than the threshold. The system has the following two big shortcomings:

- It does not check whether the input question is correct or not. It considers only the question is complete or not. 
366

367

368

369

370

371

372

373

374

375

376

377

378

379

380

381

382

383

384

385

386

387

388

389

390

391

392

393

394

395

396

397

398

399

400

- Based on the question score, the system gives the feedback. This puts forward a big issue. If the learner lacks knowledge and language skills, she will not be able to frame logical or conceptual questions completely or correctly. This leads to different answers which the learner may not agree with.

To address the issue of checking a question's correctness, we have proposed a methodology that is more precise and practical. Further, an automatic navigation system is proposed that allows the learner to select the correct question nearly matching with her intent.

\section{Assessing the Correctness of the Learners' Input Questions}

In this section, we present the proposed work for assessing whether the learner's input questions to the query-based learning system are correct or not.

\subsection{Theoretical Background}

The fundamental concepts that we adopted to assess the correctness of a question are the n-gram and sequential pattern mining. The basics of these concepts are briefed below.

\subsubsection{N-gram}

The n-gram is a sequence of $\mathrm{n}$ items adjacent to each other in a string of tokens (text). The items in the string could be letters, syllables, or words. The size of n can be 1 (uni-gram), 2 (bi-gram), 3 (tri-gram), and so on. For example, in the string "the world is a beautiful place", the possible bigrams are "the world", "world is", "is a", "a beautiful", and "beautiful place". Similarly, for the sentence "a document consists of many sentences", the word-based tri-grams will be "a document consists", "of many sentences". The tri-grams can also be overlapping like "a document consists", "document consists of", "consists of many", and "of many sentences". The same applies to the other higher-level n-grams.

\subsubsection{Sequential Pattern Mining}

The sequential pattern is a set of items that occur in a specific order [66] [67]. Sequential data patterns reflect the nature and situation of data generation activity over time. The existence of frequent subsequence totally or partially ordered is very useful to get insight knowledge. These patterns are common and natural, for example, genome sequence, computer network, and characters in a text string [68].

Sequential pattern mining (SPM) is the process of extracting items of a certain sequential pattern from a base or repository [66]. Additionally, it helps to find the sequence of events that have occurred and the relationship between them, and the specific order of occurrences. Formally, the problem of subsequence in SPM is described as, for a sequence is an ordered list of events, denoted $\left\langle\alpha_{1} \alpha_{2} \ldots \alpha_{n}>\right.$. Given two sequences $P=\left\langle x_{1} x_{2} \ldots x_{n}\right\rangle$ and $\left.Q=<y_{1} y_{2} \ldots y_{m}\right\rangle$, then $P$ is called a subsequence of $Q$, denoted as $P \subseteq Q$, if there exist integers $1 \leq j_{1}<j_{2}<\ldots<j_{n} \leq m$ such that $x_{1} \subseteq y_{j 1}, x_{2} \subseteq y_{j 2}, \ldots$, and $x_{n} \subseteq y_{j n}[67]$ [69]. 
401

402

403

404

405

406

407

408

409

410

411

412

413

414

415

416

417

418

419

420

421

422

423

424

425

426

427

428

429

430

431

432

433

434

435

436

437

\subsection{Need for Using Tri-gram based Pattern Matching}

In this section, we justified the application of n-gram pattern matching and specifically the trigram for assessing the correctness of a learner question.

\subsubsection{N-gram based Pattern Matching for Question's Correctness Assessment}

Typically, the faults in an ill-framed user question lie in the sentence structure (missing subject or verb/phrase error), syntactic structure (grammatical error like subject-verb agreement, error related to the article, plural, verb form, preposition), and semantic errors (incorrect usage and placement of word).

Domain-specific questions are interrogative sentences that specify entities, concepts, and relations (between themselves) in a particular sequence. The sequential pattern focuses on how the concepts and entities are related and what interrogative meaning can be inferred from them (the question intention). Word collocation, like words around the entities, concepts, relations together, makes word clusters. The link between the different word clusters in sentence subsequences would enable us to get insight into the structural and semantic aspects of a question. In this direction, pattern match for finding the correct word clusters and their sequences could be a prospective approach in the assessment of a question.

The n-gram language model allows for pattern matching and probability estimation of $n$-words in a sentence. The high probability of n-gram pattern similarity match could lead us to assume that n-word cluster for a subsequence in a sentence is correct for their syntactic structure and semantic composition. If the entire sentence is split into an ordered sequence of n-gram subsequences, the aggregated probability estimation of correctness for each n-gram could lead us to assume the correctness of the entire question. Hypothetically, if we consider the probability estimation of the correctness is a cumulative assessment of individual n-gram sequences in the question, then which n-gram should be chosen for the optimum result? We shall try to find the answer to this in the next subsection.

\subsubsection{Tri-gram: The Preferred Choice for Language Modeling}

In n-gram, increasing the $\mathrm{n}$ value would result in clustering an increased number of words as a sequence and thus decreasing the total number of subsequences in a sentence. This leads to an increase in biasness toward similarity pattern matching and thereby decreases the similarity matching probability of diverse sequence patterns. Whereas decreasing $n$ increases the number of subsequences in a sentence, thereby increasing the probability of similarity match at smaller sentences, but fails to find cohesion among word clusters and hence decreases the probability of accuracy for the larger sentences.

A tri-gram is a perfect capture for the desired features of the sentences and, at the same time, maintaining the optimum complexity factor of the program. While resoluting the sense from a group of words in sequence, it is observed that tri-gram (given one word on either side of the word) is more effective than two words on either side (5-gram). It is also found that increasing or 
438

439

440

441

442

443

444

445

446

447

448

449

450

451

452

453

454

455

456

457

458

459

460

461

462

463

464

465

466

467

468

469

470

471

472

reducing the word on either side of a given word does not significantly make it better or worse in n-gram sequencing [70].

\subsection{Question's Correctness Assessment Using Tri-gram Approach}

In this section, we present the proposed approach for assessing the correctness of the learner question using tri-gram. The method includes building a tri-gram language model that is trained to assess the correctness of a question on Java, and devising a classification method to separate correctly and incorrectly framed questions. The details are described in the following subsections.

\subsubsection{Tri-gram Language Model Generation}

The specific procedures for generating the tri-gram based language model are explained in the following. The process flow of the language model generation is shown in Fig. 2.

Figure 2. Steps for language model generation

\subsubsection{Data Collection and Corpus Preparation}

The language model is designed, trained, and tested on a corpus of sentences. To build the needed corpus, we collected a total number of 2533 questions on the various topics of Java from books (available as hardcopy and softcopy), blogs, websites, and university exam papers. We adopted both manual and automatic approaches to extract and collect the questions. A group of four experts in the Java language was involved in the manual collection of questions. For automatic extraction, we used a web crawler with a question parser. The crawler, an HTML parsing program designed in Python language, reads the webpage and spawns across other inbound webpages. Using the appropriate regular expression, the expected question sentences were extracted from the parsed pages. The returned texts were then manually verified and corrected, if required, to obtain meaningful questions.

To test the efficiency of the proposed method in rightly identifying a correct and incorrect question, we needed a set of wrong questions as well. A number of incorrectly framed questions were collected from learners' interaction with the online learning portals and institutional online learning system and questions asked by the students in the class. The incorrect questions contain grammatical errors (sentence structure and syntactic errors) and semantic errors.

The details of the question datasets are as following:

- Number of questions in training dataset: 2533 (all correct)

- Number of questions in testing dataset: 634

- Number of correct questions in testing dataset: 334

- Number of incorrect questions in testing dataset: 300 


\section{3}

474

475

476

477

478

479

480

481

482

483

484

485

486

487

488

489

490

491

492

493

494

495

496

497

498

499

500

501

502

503

Figure 3. Typical steps for preprocessing a question

\subsubsection{Data Preprocessing for Language Model Generation}

As the collected questions consisted of many redundancies and anomalies, we preprocessed them to develop a suitable language model for questions. Text preprocessing typically includes steps like stopword removal, lemmatization, etc. Stopwords are frequently used words like "I", "the", "are", "is", "and", etc., which provide no useful information. Removing these from a question optimizes the text for further analysis. However, sometimes certain domain-specific keywords coincide with the stopwords, removal of which may result in a loss of information from the questions. Therefore, we modified the list of stopwords by removing the domain-specific keywords from the Natural Language Toolkit $\left(\mathrm{NLTK}^{1}\right)$ stopword list to avert eliminating the required stopwords. The modified NLTK stopword list is used to remove stopwords from the questions, excluding those which are meant for the Java language.

Each question is broken down in the form of tokens using the regular expression tokenizer, which is present in the NLTK library. Each of these tokens is converted into their stem (root word) form using the Wordnet Lemmatizer to reduce any inflectional form of words. The steps for preprocessing an input question are shown in Fig. 3.

\subsubsection{Language Modeling}

The preprocessed questions are broken down into sets of distinct uni-, bi-, and tri-gram sequences. The uni-gram set is built on individual tokens in the questions. Whereas the bi- and tri-grams are formed using overlapping word sequences sentences, along with the usual two- and three-token sequences, respectively, as shown in Fig. 4.

Figure 4. Generating uni-gram, bi-gram, and tri-gram sequences from a question

The respective count of each n-gram occurrence is obtained from the question corpus. Along with the count, based on the relative occurrences in the corpus, the unconditional log probabilities of each uni-gram, as represented by Eq. 1, and conditional log probabilities of each bi- and tri-gram, as represented by Eq. 2 and Eq. 3, respectively, are calculated.

$P\left(w_{1}\right)=\log \left(\frac{C\left(w_{1}\right)}{C\left(w_{n}\right)}\right)$

${ }^{1}$ https://www.nltk.org/ 
504 Where $w_{n}$ represents the words in the corpus and $c\left(w_{n}\right)$ returns the count of the total number of 505 words in the corpus.

$506 P\left(w_{2} \mid w_{1}\right)=\log \left(\frac{C\left(w_{1}, w_{2}\right)}{C\left(w_{1}\right)}\right)$

$507 P\left(w_{3} \mid w_{1}, w_{2}\right)=\log \left(\frac{C\left(w_{1}, w_{2}, w_{3}\right)}{C\left(w_{1}, w_{2}\right)}\right)$

508

509

510

511

512

513

514

515

516

517

518

519

520

521

522

523

524

525

526

527

528

529

530

531

532

533

The log probabilities in Eq. 1 and Eq. 2 allow transforming higher fractional probability values to lower ones, which are easy to be used in the computation. A sample representation of the language model is shown in Table 3. The entire language model derived from the question corpus is saved in $\mathrm{ARPA}^{2}$ format.

2

3

$$
\text { Table 3. Uni-gram, bi-gram, and tri-gram probabilities for a question }
$$

\subsubsection{Classifying Correct and Incorrect Questions}

The correctness of a question is estimated based on its syntactical and semantic aspects and accordingly is classified as correct or incorrect. The complete process of identifying correct and incorrect questions is pictorially shown in Fig. 5.

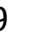

Figure 5. The flow diagram for identifying correct and incorrect questions

\subsubsection{Preprocessing the Learners' Input Questions}

The input questions from the learner are preprocessed to remove the stopwords and the irrelevant words. Also, lemmatization is carried over the input question.

\subsubsection{Probability Estimation for Question Correctness based on the Syntactical Aspect} After preprocessing, the question is broken down into overlapping tri-gram sequences. Each trigram sequence is estimated for probability by maximum likelihood estimation (MLE) from the language model. If a tri-gram sequence of the question is not present in the language model, it will lead to zero estimation. However, though the entire tri-gram sequence may not occur in the language model, a partial word sequence, a lower-order n-gram (bi-gram) of it, could be valid. The Backoff approach [71] [72] is considered for tri-grams to take into account of sequence which counts to zero. The tri-gram sequences which estimate to zero are further estimated for their bigrams. The probability of a tri-gram is depicted in Eq. 4

\footnotetext{
${ }^{2}$ http://www.speech.sri.com/projects/srilm/manpages/ngram-format.5.html
} 
$P\left(w_{3} \mid w_{1}, w_{2}\right)=\left\{\begin{array}{c}\frac{c(w 1, w 2, w 3)}{c(w 1, w 2)}, \text { if } c(w 1, w 2, w 3)>0 \\ 0.5 \times\left(\frac{C\left(w_{1}, w_{2}\right)}{C\left(w_{1}\right)}+\frac{C\left(w_{2}, w_{3}\right)}{C\left(w_{2}\right)}\right), \text { if } c(w 1, w 2, w 3)=0\end{array}\right.$

535

536

537

538

539

540

541

542

543

544

545

546

547

548

549

550

551

552

553

$554 \quad E_{s m}=\frac{1}{k} \sum_{i=1}^{k} P_{i}$

\section{5}

556

557

558

559

560

561

562

563 sentence.

$E_{s y}=\frac{1}{k} \sum_{i=1}^{k} P_{i}$ is shown in Eq. 7.

The probability of each tri-gram ranges from $0<=\mathrm{P}<=1$. A higher probability refers to more correctness and higher occurrence. The entire probability of syntactic correctness of the sentence can be obtained as the addition of probability of each tri-gram in the question in Eq. 5, where $\mathrm{k}$ is the number of tri-grams in the question and $\mathrm{P}_{\mathrm{i}}$ is the probability of the $\mathrm{i}^{\text {th }}$ tri-gram sequence in the

\subsubsection{Probability Estimation for Question Correctness based on Semantic Aspect}

The correctness of question semantic is assessed by estimating the validity of individual overlapping tri-gram sequences of the sentence. The validity of the tri-gram is assessed by the probability estimation of each tri-gram sequence in question found matches in the language model, as shown in Eq. 6. The semantic correctness of a question is estimated on the full similarity match of each tri-gram sequence. More the number of subsequences of the question sentence matches the language model, more is the chance of the question being semantically correct. The overlapping tri-gram sequences reflect the cohesion among words in the sentence subsequences. Thus, increasing the number of matching of the tri-gram sequences establishes a higher probability of semantic accuracy of the question. The semantic correctness of the question is calculated as the summative average of probabilities of each tri-gram sequence in the sentence

$P\left(w_{3} \mid w_{1}, w_{2}\right)=\left\{\begin{array}{l}1, \text { if } P\left(w_{3} \mid w_{1}, w_{2}\right)>0 \\ 0, \text { if } P\left(w_{3} \mid w_{1}, w_{2}\right)=0\end{array}\right.$

\subsubsection{Classification}

The correctness of a question is calculated by Eq. 8, where $E_{s y}$ and $E_{s m}$ are the probability estimates of syntactical and semantic correctness of the sentence, respectively. A syntactically correct question has $E_{s y}=1$, and $E_{s m}=1$ for semantically correct. Hence, the standard score for a correct question is $1+1=2$. Thus the degree of correctness $\left(C_{d}\right)$ of the question with respect to the complete correctness (i.e., 2) is assessed by adding the calculated probability estimates $E_{s y}$ and $E_{s m}$ and subtracting from 2 . We considered the question is correctly structured, if $C_{d} \leq 20$; otherwise, the framing of the question is not correct.

$C_{d}=\left(2-\left(E_{s y}+E_{s m}\right)\right) \times 50$ 
5643.4 Experiment and Performance Evaluation for Question's Correctness Assessment

565 The evaluation of the performance measure of the proposed approach for assessing the

566 correctness of the learner question is done on a corpus of 634 annotated questions, where $52 \%$ of

567 questions are correctly framed. The performance of the tri-gram approach for classifying

568 questions as correct or incorrect is measured based on the metrics: true positive, true negative,

569 false negative, and false positive, and the performance measures: Accuracy, Precision, Recall,

570 F1-Score, as shown in Table 4.

571

572

Table 4. Performance measures of the proposed approach

573

574 In the experiment, we attempted to distinguish between correct and incorrect questions based on

575 the probabilistic calculation proposed by our approach. The experimental results show that our

576 method fails to classify 50 of these questions correctly. Out of these 50 questions, 32 were

577 correct questions but are identified as incorrect. Further analysis of these false-negative questions

578 reveals that after preprocessing and stopword removal, the length of most of the questions is

579 reduced to less than three. These questions fail to generate any tri-grams to perform the

580 probabilistic calculation. So, these questions by convention get marked as incorrect. Some of

581 these false-negative questions even belong to domains that are not present in the training dataset.

582 As a result, the proposed method fails to identify these questions correctly. The other set of

583 incorrectly classified questions comprises incorrect questions which are marked as correct. The

584 false-positive questions primarily have misplaced punctuation marks which results in the

585 structure of the incorrect question identical to the correct questions in the training set. They form

586 tri-grams or bi-grams, which perfectly match the tri-grams or bi-grams from the language model

587 and render a high probabilistic score for the question. A margin of $8 \%$ error shows the efficiency

588 of the proposed approach.

589 The efficacy of the tri-gram model approach was compared with other n-grams. The models

590 were trained over the same question dataset to keep the experiment bias-free. Figure 6 shows a

591 comparison of the accuracy measures obtained for each n-gram approach over the same

592 statistical calculation. It is evidently seen that the accuracy of tri-gram is far better than other n-

593 grams. The accuracy decreases with the increasing value of $n$ in n-gram. It leads to biased

594 higher-order word sequence pattern search and fewer options for pattern assessment at lower

595 orders. This causes restricted pattern search and a decrease in accuracy. Similarly, decreasing $n$

596 leads to word sequence pattern search at lower order, which restricts the probability of

597 correctness of the word sequences at higher orders. This typically reduces the accuracy. The

598 comparative experiment thus concludes that the use of the tri-gram model for question

599 assessment leads to better assessment results.

600

601

Figure 6. Accuracy comparison of the four n-gram approaches 
603 The result of the proposed approach is compared with the result of other research work [30]. 604 Ganesh et al. [30] applied a tri-gram based approach to detect an error in English language 605 sentences. Table 5 shows the result comparison in terms of four assessment metrics. From the 606 table, it is evident that the accuracy of our proposed approach is much better. However, the 607 precision of both approaches is the same. This establishes the true positive and true negative 608 identification cases are better in our approach for detecting the errors and thus the correctness or 609 incorrectness of the question sentences.

610

Table 5. Comparative results of the proposed approach and the solution given in [30]

612

\section{Guiding the Learner to the Probable Correct Question} In the previous section (Section 3), we checked if the question given as input by the learner to the query-based learning system is syntactically and semantically correct or not. If the question is not correct, we guide the learner to the probable correct question that she actually intended to ask through one or multiple steps of question suggestions. The detailed methodology and framework of the proposed work are discussed in the following subsections.

\subsection{Similarity-based Recommendation for Mitigating Incorrect Learner Question} followed in literature. But the success is limited and restricted to correcting only a few types of errors or mistakes. The typical mistakes a learner commits while articulating a question are shown in Fig. 7. For instance, inappropriate word selection may not reflect the exact intention of the learner. Similarly, insufficient keywords may not express the intended concept.

In regard to these, except for grammatical and sequential ordering errors, auto-correction for other types of errors is not possible. The other way around, the problem is suggesting correct questions to the learner which are near to what she intended to ask. Suggesting correct questions which are similar to information and morphological structure to the given question could lead to having a chance that learner may found the right question which she intends to ask. Considering the information like the concepts and functional words which are used in compiling the question is best of her knowledge in the current information seeking situation, the learner could be recommended appropriate questions which are aligned to/with the information they are seeking for. Thus, suggesting correct questions in contrast to the incorrect question imposed by the 
638

639

640

641

642

643

644

645

646

647

648

649

650

651

652

653

654

655

656

657

658

659

660

661

662

663

\section{4}

665

666

667

668

669

670

671

672

673

674

675

question problem.

\subsection{Issues in Similarity-Based Recommendation of Questions}

Cosine and Jaccard similarity techniques are the two text-based similarity approach which has been widely incorporated for finding similar text [73] [74]. But these approaches, when applied to question-based corpus for identifying similar question text, lead to the recommendation issues, as discussed in the following subsections.

\subsubsection{Information Overload}

Text similarity based on word match searches for similarity for every occurring word in the source sentence-incorrect question text for an exact match in the questions present in the question corpus. The needful comparison based on matching word occurrence among the sentences returns similar text. Since the question framing is incorrect, taking a part of the entire sentence which seemingly founds to be correct and conveys the learner's intent, could lead to a better similarity match. However, the prevailing constraint and limitations of NLP fail to analyze and identify the parts of the source sentence, which are correct as per learner intention. Failing to determine this leads to ambiguity in identifying the parts of a sentence that are to be taken correctly for similarity match. Without this knowledge, the similarity search is done for each occurring word (assuming they are correct as per the learner intent) in the question against the questions in the corpus lead to a huge set of information. For example, a learner questions on Java with incorrect word ordering and missing words like "What different are interface implement", when runs for similarity match like Jaccard similarity on a question corpus returns a lot of information, as shown in Table 6. With this amount of information, the learner may get confused and lost.

Table 6. Similar questions returned by Jaccard similarity for the learner question "what different are interface implement"

\subsubsection{Diverse Information}

A learner, when composing a question, intends to seek information limited to a particular topic(s). Text similarity based on word match searches for similarity for every occurring word in the source sentence for an exact match into the question corpus. For similarity measurement, weightage is given to word occurrence frequency rather than on their subject domain relevancy. No consideration is given to individual tokens belonging to a topic of a domain. Since a question is made up of functional words (noun or verb) along with concepts (domain keywords), the word match found for every functional word in the corpus leads to different questions having different topics which the learner does not intends to seek. This results in questions that are beyond the search topic boundary, leading to diversification of information. For example, the similarity search for an incomplete question like "access modifier in Java" using Jaccard similarity returns questions of different topics, as shown in Table 7. Figure 8 shows the share of the number of 
676 questions belonging to different topics for the given similarity recommendation. A large number 677 of questions are on a different topic than that of the input question. This may put the learner in 678 jeopardy and confusion. Conclusively, the similarity match on functional words of the source 679 question in the corpus may result in diversification instead of convergence.

680

Table 7. Recommended list of question and their topic retrieved using Jaccard similarity for the incorrect input question "access modifier in Java"

683

Figure 8. Returned similar questions belonging to different topics by Jaccard similarity

685

686

687

688

689

690

691

692

693

694

695

696

697

698

699

700

701

702

703

704

705

706

707

708

709

710

711

712

\subsubsection{Biased to Exact Word Match}

While framing a question, keywords and functional words are integrated and sequenced in an appropriate manner to make meaning out of the question. The use of these words by the learner is the natural outcome of the learner's knowledge and communication skill. And as a reason, lack of a learner's expertise does not assure the correctness of question framing. The similarity assessment technique performs an exact word match. This will return only those questions, the words of which are exactly matched (word-by-word) with the learner's input question. This results in obscuring many other similar questions, which are having different words but similar or near to similar meanings. And thus, many of the questions having similar meanings but having different word construction are ignored, resulting in poor efficiency.

\subsection{Proposed Framework for Correct Question Suggestion to the Learner}

Considering the above-mentioned three problems, we have adopted the soft cosine technique to find similar sentences. The similarity matching is augmented by question selection and iteration pass. We propose a similarity assessment framework for suggesting the correct question for a given incorrect question on a particular domain. The framework consists of three phases of working, as discussed below. The framework is shown in Fig. 9, while the process flow is shown in Fig. 10.

Figure 9. The proposed framework for correct question suggestion to the learner

Figure 10. The flow diagram for suggesting correct questions to the learner

\subsubsection{Selecting Questions with Similar Concepts}

The selection of questions with similar concepts limits the search boundary, and hence the diverse information issue can be addressed. Learners impose questions using the best of their 
713 knowledge. This makes them use concepts that are more aligned with the information they are

714 trying to seek. Though not all the concepts which are articulated in the question are rightly

715 chosen, the probability of having the required concept in the question also persists. And thus,

716 claiming all questions from the corpus having the same concept(s) as present in the source

717 question could increase the likelihood of finding the right intended question. This also reduces

718 the probability of recommending questions that are completely on a different topic(s) or

719 concept(s) not relating to the concept(s) present in the source question. As a reason, the concept-

720 wise selection of questions will reduce the diversification of information recommendation.

721

722

723

724

725

726

727

728

729

730

731

732

733

734

735

736

737

738

739

740

741

742

743

744

745

746

747

\subsubsection{Similarity Assessment and Correct Question Recommendation}

A learner may compose an incorrect question due to the following three reasons:

a) There are insufficient keywords to express the question.

b) Insufficient number of words used to express the question.

c) The selection of words and their usage may be incorrect.

In all the cases, we need to find the alternative questions closest to the learner's intended question. For estimating the similarity, we suggested looking for the questions that have the same or similar word features as the learner's question. A hard similarity (word to word) match for word features between the incorrect and alternative question reduces the chances of getting a more accurate alternative. Moreover, conducting a hard similarity search in the word feature space of the correct question, the source question's inappropriate words would be of no use. Rather a soft similarity (synonym or close related words) match would give a high probability of finding the questions that are meaningfully aligned to the learner's intent. To address the similarity match problem and to find the correct question, we applied soft cosine measures. Soft cosine allows finding the questions that are significantly similar in terms of the semantic matching, irrespective of the exact word match.

The similarity measure $\operatorname{sim}\left(\mathrm{f}_{\mathrm{i}}, \mathrm{f}_{\mathrm{j}}\right)$ in soft cosine calculates the similarity for synonym or relatedness between the features $f_{i}$ and $f_{j}$ of the vectors under consideration. Here, the vector is a question, and the words of the question represent its features. A dictionary approach like WordNet::Similarity is being used to calculate the similarity (or relatedness) among the features [75].

From the n-dimensional vector space model's perspective, the soft cosine measures the semantic comparability between two vectors. It captures the orientation (the angle) between the two vectors. But unlike cosine similarity, the features are projected in an n-dimensional space so that similar features are close by with very less angle difference. This causes the meaningfully similar words (features) of vectors (questions) to have minimal angle differences [76], as shown in Fig. 11. The equation for soft cosine is given in Eq. 9. 
748

$$
\operatorname{Soft} \_ \text {cosine }(p, q)=\frac{\sum_{i, j}^{N} S_{i j} p_{i} q_{j}}{\sqrt{\sum_{i j}^{N} S_{i j} p_{i} p_{j}} \sqrt{\sum_{i j}^{N} S_{i j} q_{i} q_{j}}}
$$

751

752

753

754

755

756

757

758

759

760

761

762

763

764

765

766

767

Where, $S_{i j}$ is the similarity between the features $i$ and $j$, and $p$ and $q$ are the input question and the correct question, respectively.

Figure 11. Comparison between cosine and soft cosine A) orientation between vectors in cosine similarity B) orientation between vectors in soft cosine measure

\subsubsection{Iteration and Question Selection}

To overcome the issue of information overload, ten questions whose similarities are found more than $50 \%$ in relation to the source question text are enlisted to choose by the learner. This allows the learner to focus much on what he is actually seeking rather than getting overwhelmed by the huge information which would have been recommended otherwise. Since the approach is probabilistic, chances are there that no right question which is close to learner intention is found in the list. In such a case, selecting a question from the recommended list nearer to the question which learner intends to seek would allow the system to have better-informed data. The learner selected questions that, in turn, act as a seed for further similarity search. Considering the selected question (seed question) as new input for further similarity search would actually converge the search boundary and increase the homogeneity of information. This will reduce diversification. With every recommendation pass, the degree of concept-wise similarity increases, which, in turn, increases the range of similar questions. This makes the question suggestion to shift closer to the learner's intention. The complete process is presented in

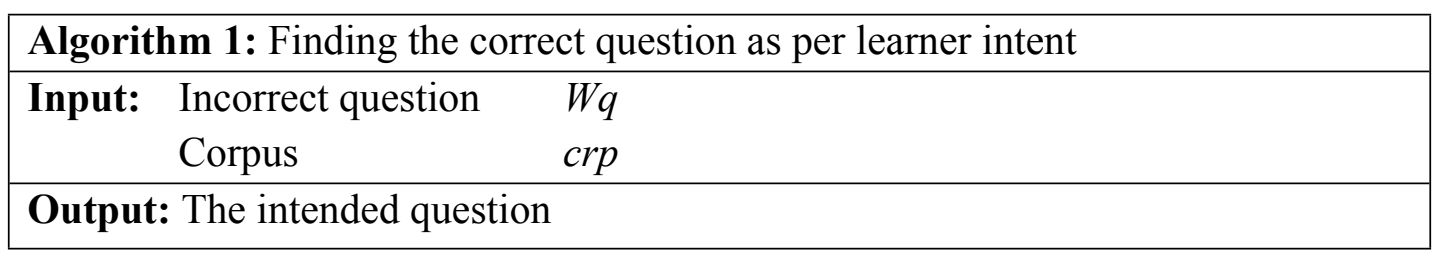

Algorithm 1. 


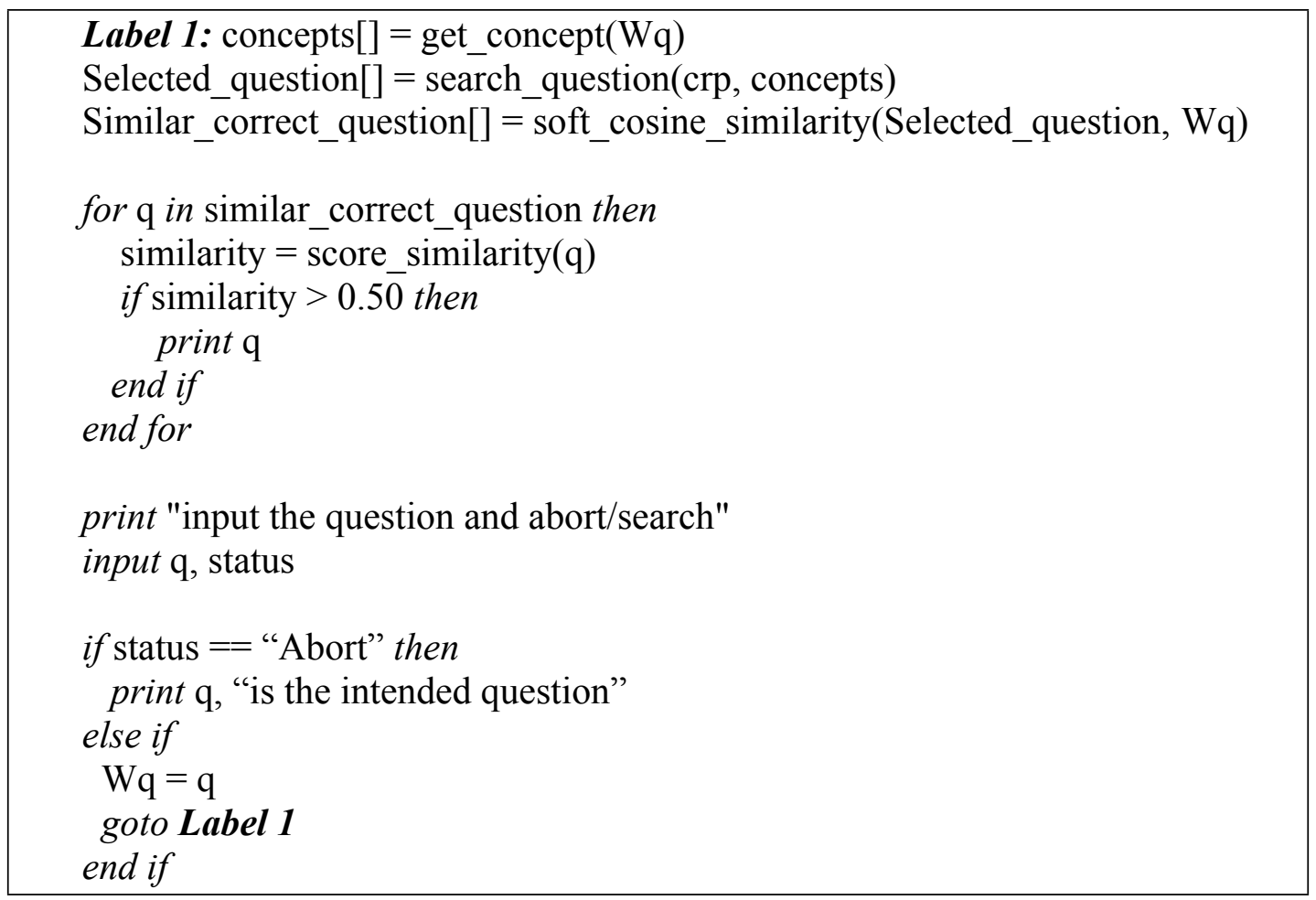

768

769

770

771

772

773

774

775

776

777

778

779

780

781

782

783

784

\subsection{Experiment for Correct Question Suggestion}

\subsubsection{Experimental Procedure}

For experimentation and performance analysis, the proposed methodology for similarity assessment and recommendation of correct question is implemented as a web-based client/server model, as shown in Fig 12.

Figure 12. The web (client/server) model used to implement the proposed framework

The server contains the web application (WebApp) with the requisite HTML and Python file, Flask $^{3}$ framework, and Python (version 3.8). Flask is a web application microframework that allows to delegate web pages over the network and handle learner's input requests. The framework is glued as a layer to Python for executing the processes. The model is implemented in Python and is deployed in WebApp as a Python file. Further, the learner's different interactions with the system are stored as the experimental data in the SQLite database, which comes default with Python.

The web server is connected to the client devices over the internet or LAN to exchange HTTP Requests and HTTP Responses. And, the learner (client) interacts with the model through the webpage, as shown in Fig. 13. The reason behind choosing this web model for the experiment is

\footnotetext{
${ }^{3}$ https://flask.palletsprojects.com/en/1.1.x/
} 
as follows:

- Python programs allow for text-based interaction, which disinterests learners, making them less attentive. This causes lacking full involvement of the learner. In contrast, a web-based model gives a graphical interface for interaction and thus better involvement of the learner.

- Since the experiment involves many learners, a web-based model allows them to participate in the experimentation from anywhere and anytime. This gave the learner more freedom to choose the place and time of their own to take part in the experimentation. Moreover, this web model allows multiple candidates to simultaneously participate in the experiment from different client devices while the experimentation result is getting stored centrally.

Selection of the questions based on the concept, and followed by similarity assessment, is carried out in the server. Three similarity assessment techniques - soft cosine, Jaccard, and cosine similarity are used to find the intended correct questions from the corpus. These three techniques are followed in parallel for assessing their performance for the given incorrect input questions. For this experiment, we used the complete training corpus (i.e., 2533 questions).

To select the probable correct question from the recommend similarity list, a threshold of 0.5 is considered as the minimum similarity score for soft cosine, while 0.2 is considered for Jaccard and cosine. It was found that Jaccard and cosine similarity techniques returned either no or very few (one or two) similar questions, which were not suitable for carrying out the experiment. Further, in some cases, while searching for similar questions to the given incorrect question, the same question is iteratively returned for each consecutive pass. As a reason, in the cases of Jaccard and cosine, the threshold for similarity score is reduced to a lower value of 0.2 . This gave some outputs needed to carry out the experiment and compared to the result of soft cosine.

Figure 13. The user interface for learner interaction

\subsubsection{Learner Verification}

The performance of the framework for similarity-based recommendation to find the intended question was verified by manual assessment. The assessment was carried by a group of learners. A total of 34 students of the CSE department at Bengal Institute of Technology, studying Java in their $6^{\text {th }}$ semester of the B.Tech degree program, were selected. The students chosen were low scorers in the subject. The rationale behind choosing these students was that we wanted to select learners who are aware of the Java language and its terminology but are neither expert nor good in the subject. This made them suitable candidates as they were susceptible to compose incorrect questions. 
821 Each student was instructed to inputs approximately three incorrect questions, totaling 100.

822 Corresponding to each question, three recommendations are made using the soft cosine, Jaccard,

823 and cosine similarity techniques, as shown in Fig. 13. If the student found the correct intended

824 question, the iteration was stopped for the respective similarity technique. If the intended

825 question was not found in the recommended list, the student chose a question from the list as a

826 seed question that was close to the intended question, and another iteration or pass was followed.

827 If the intended question was not found within three passes, the recommendation process for the

828 respective individual similarity technique was stopped. The purpose of using three similarity

829 techniques is to make a comparison and find the best performance among the three.

\section{$830 \quad 4.5 \quad$ Result and Analysis}

831 4.5.1 Accuracy

832 The learner input and feedback on a total of 100 incorrect questions are shown in Table 8. The

833 learner acceptance result of finding the intended correct question against the incorrect input

834 question is summarized and shown in Fig. 14. The summarization is made on the basis of

835 whether the learner finds the intended question or not for each of the three similarities-based

836 recommendations.

837

838

839

840

841

842

843

844

845

846

847 Accuracy $=\frac{A \times 100}{B}$

Where, question.

Table 8. Similarity recommendation against learner questions

Figure 14. Comparing the correct question recommendation based on three similarity metrics A) Soft-cosine B) Cosine C) Jaccard

Based on learner input and the system feedback, the framework is evaluated for the accuracy metric. The accuracy is an intuitive performance measure, a ratio of correct observation made to the total observation made. The accuracy is defined in percentage by Eq. 10 .

- $\mathrm{A}$ is the number of observations made where the learner finds the correct intended

- $\mathrm{B}$ is the total number of questions taken for observation.

The overall accuracy result of the framework corresponding to the soft cosine, Jaccard, and cosine similarity techniques is shown in Fig. 15. 
855

856

857

858

859

860

861

862

863

864

865

866

867

868

869

870

871

872

873

874

875

876

877

878

879

880

881

882

883

884

885

886

887

888

889

890

891

892
Figure 15. Accuracy comparison for similar question recommendation of three similarity measures

The accuracy results for learners accepting the recommended question show that soft cosine similarity outperforms the cosine and Jaccard similarities. In the given experimental data set, the soft cosine based recommendation returns the correct result in two or more passes for 12 input questions. While, for the other 73 input questions, it returns the result in one pass. Therefore, it can be concluded that though the soft cosine similarity-based recommendation returns the intended question in one pass for the maximum number of questions, recommending results in two or more passes is unavoidable. It is observed that input questions lacking sufficient information cause the recommendation system to iterate multiple passes of learner's interaction to reach the intended question. The hefty size of the corpus might be another reason for the increased number of passes.

The results also show that for 15 input questions, the soft cosine similarity-based recommendation fails to find the correct question matching to learner's intent. It is observed that in very few cases where the words in the input question are highly scrambled or out of sequence, it may cause the soft cosine to fail to find the correct questions. In this case, the Jaccard similarity outperforms the soft cosine. The other reason which contributes to soft cosine failing is the string length of the input question. If the string length is reduced to one or two words after stopword removal in question preprocessing, the soft cosine based recommendation is unable to find the exact intended question from the huge number of questions within a limited number (three passes) of learner's interaction. Perhaps a greater number of interactions were needed. Besides these two structural issues on input questions, the soft cosine has some inherent limitation which causes the recommendation set to fail in retrieving the appropriate questions near to learner intention. Even though it is claimed that soft cosine works well on word similarity, actually, it does not do well for multiple synonyms while matching for similarity. The other inherent issue is that the soft cosine fails to infer the common-sense meaning from a sequence of words or phrases to find semantical similarity.

\subsubsection{Diversity and Evenness}

Soft cosine technique with every iteration converges the search for questions on a particular topic. This causes the recommended questions to be very much focused on the intent of the input question. To assess the effectiveness of soft cosine in each pass, the iteration result of the recommended question list, obtained by the three similarity assessment techniques, is analyzed for diversity and evenness. The diversity specifies how the questions in the recommended list are diverse in terms of topic. Where the evenness specifies how evenly the topic information (concepts) are spread (distribution) in the recommended list. The diversity and the evenness of information in the recommended list of questions in each pass are calculated by Shannon's diversity index $(\mathrm{H})$ and Shannon's equitability $\left(\mathrm{E}_{\mathrm{H}}\right)$, respectively, as given by Eq. 11. and Eq. 12. 
$893 \quad H=-\sum_{i=0}^{n} \mathrm{P}_{\mathrm{i}} \ln \mathrm{P}_{\mathrm{i}}$

894 Where, $n$ is the number of topic category and $P_{i}$ is the proportion of the number of $\mathrm{i}^{\text {th }}$ topic

895 relative to the total count of individual topics for all questions in the recommended list.

$896 E_{H}=\frac{H}{\ln S}$

897

898

899

900

901

902

903

904

905

906

907

908

909

910

911

912

913

914

915

916

917

918

919

920

921

922

923

924

925

926

927

928

929

930

931

932
Where, $\mathrm{S}$ is the total count of individual topics for all questions in the recommended list. The evenness value assumes between 0 and 1, where 1 denoting completely even. In an ideal situation, $\mathrm{H} \approx 0$ specifies that topic in recommendation question list is not diverse and all recommended question focuses on one topic. Similarly, $\mathrm{E}_{\mathrm{H}} \approx 0$ specifies zero dispersion of topics in the recommended question list.

The changes in diversity and equitability indices along to each pass for a given incorrect question "java not have destroy and how garbage collect" are discussed below.

a) Each keyword in the source question denotes a concept which in turn relates to a topic. The keywords in the question are used to select and group questions from the corpus belonging to the same topic domains. The incorrect question is matched with the grouped question using the soft cosine measure. The set of suggested questions returned by the soft cosine similarity measure in the first pass is shown in Table 9. Each keyword in the recommended similar question list reflects a concept which accounts for a count of the respective topics. Based on which the $\mathrm{H}$ and $\mathrm{E}_{\mathrm{H}}$ are calculated for the list as given in Table 10.

b) The learner chooses the question "explain garbage collection in java programming" from the recommended list of questions which is closest to her intent as the seed question for further searching.

c) In the second pass, again, based on the keywords from the source question, the questions on the same topic are selected and grouped from the corpus. The set of suggested questions returned by the soft cosine similarity for the selected question against the selected source question is shown in Table 11.

Table 9. Suggested similar questions from the first iteration (pass 1)

Table 10. Diversity and evenness measures from the pass 1

Table 11. Suggested similar questions from the first iteration (pass 2) 
933 Based on the individual topic count and the total topic count, the $\mathrm{H}$ and $\mathrm{E}_{\mathrm{H}}$ are calculated for the 934 list, as given in Table 12. It is evident that the diversity index $\mathrm{H}=1.02$ in pass 1 is reduced to $935 \mathrm{H}=0.85$ in pass 2 . This implies that the diversity of topic information found in the recommended

936 list decreases along with the passes. This signifies the search information space converges, which

937 give learner to be focused and better options to select the question from the list. Further, the 938 evenness $\mathrm{E}_{\mathrm{H}}=0.985$ in pass 1 is reduced to $\mathrm{E}_{\mathrm{H}}=0.781$ in pass 2 . This implies that the unevenness 939 of topic distribution among the questions increases. This signifies that the distribution of the 940 intended topic among the question increases which give a high probability of finding the right 941 question.

942

Table 12. Diversity and evenness measures from the pass 2

The keyword-based selection and grouping of questions from corpus eliminates the otherwise irrelevant question and thereby restricts it to a reduced topic search space. Further, soft cosine

947 measure based similarity concretely shrinking the search to more meaningful questions close to the learner's intent and thereby decreasing the diversity.

From the results, a sample of nine questions that passed two iterations, applying the soft cosine similarity, was considered. Table 13 shows the diversity and evenness calculated on the topic information for the recommended question list obtained after each pass corresponding to the three similarity assessment techniques for a given question. Here, diversity and evenness equating to 0 indicate that the suggested question list belongs to the same topic. Some question searches using the similarity-based technique led the learner to find the intended question in the first pass. This made the second pass for the question search a not applicable (NA) case. From the table, it is quite clear that with every pass, the diversity in the recommended list of the question, obtained by soft cosine in comparison to other, decreases. This made us conclude that with the progression of search iteration, the search space becomes narrower; in other words, the search converges. This ensures the search result to be focused on the intended topic, which helps the learner in reaching the intended question quickly.

Table 13. Diversity index and equitability on recommended questions

\section{Conclusions and Further Scope}

A lot of emphases are given to developing and structuring the contents so that it can be attractive and motivating to learners. Due to the high-cost factor and difficulty in managing peer-to-peer support, learner-expert based interaction is being less encouraged in online systems. Questions are one of the key forms of natural language interaction with computers which gives the learner an upper hand in interacting with computers more broadly. Composing correct questions is essential from this perspective. A rightly composed question allows a clear understanding of what the learner wants to know. An incorrectly composed question raises ambiguity and 
972 diversions, which results in incorrect information. This often misleads the learner. For

973 determining the intent and objective and hence the semantics of the question, it is important to

974 know whether the question is composed correctly to its semantics. Determining whether the

975 input question is incorrectly or rightly composed would increase the accuracy of information

976 retrieval. This put the absolute requirement for verifying whether the question framing is and by

977 semantics is correct or not before it can be used for information retrieval.

978 This paper proposes an approach for assessing the validity of framing the question and its 979 semantics. A tri-gram based language model is used for assessing the question's correctness in 980 terms of syntax and semantics. The model outperforms the other n-gram approaches and 981 establishes the fact that tri-gram optimally performs well in assessing the questions. The tri-gram 982 language model exhibits an accuracy of $92 \%$, which is way higher than the accuracy shown by $2-$ 983 gram, 4-gram, and 5-gram over the same test data assessment.

984 The work also proposes an interactive framework for correct question recommendation. The 985 framework uses a soft cosine based similarity technique for recommending the correct question 986 to the learner. The proposed framework is assessed by learner questions and compared with other 987 similarity assessment techniques, viz. cosine and Jaccard. The soft cosine similarity technique 988 recommends the correct question way better than the other two, achieving an accuracy of $85 \%$. 989 In the case of multi-pass interaction, as the number of passes increased, the information diversity 990 is reduced, and the search is converged to the intended question quickly.

991 In conclusion, incorporating the presented work in an interactive OLS will not only improve the 992 performance of the system significantly but will also enhance the learner satisfaction and 993 learning focus, leading to a boosted quality of learning. The proposed approach can be used in 994 precise personalized learning recommendations and mitigating the associated cold start problem.

995 However, this work has a couple of limitations which opens up further research scopes. Since we 996 used a tri-gram based approach, it cannot assess the correctness of a question that has less than 997 three words. Also, it fails to assess the informal questions that typically comprise compound and 998 multiple sentences. Techniques like graphs (semantic network), machine learning (LSTM), etc., can be 999 explored to solve these issues.

\section{References}

1001

[1] M. Radović-Marković, "Advantages and disadvantages of e-learning in comparison to traditional forms of learning," Annals of the University of Petroşani, Economics, vol. 10, no. 2, pp. 289-298, 2010.

[2] B. C. Czerkawski, "Blending Formal and Informal Learning Networks for Online Learning," International Review of Research in Open and Distributed Learning, vol. 17, no. 3, pp. 138-156, 2016.

[3] S. Pal, P. K. D. Pramanik, T. Majumdar and P. Choudhury, "A semi-automatic metadata extraction model and method for video-based e-learning contents," Education and Information Technologies, 
vol. 24, no. 6, pp. 3243-3268, 2019.

[4] E. Herder, S. Sosnovsky and V. Dimitrova, Adaptive Intelligent Learning Environments, E. Duval, M. Sharples and R. Sutherland, Eds., Springer, Cham, 2017.

[5] C.-J. Huang, M.-C. Liu, S.-S. Chu and C.-L. Cheng, "Application of machine learning techniques to Web-based intelligent learning diagnosis system," in International Conference on Hybrid Intelligent Systems, Kitakyushu, Japan, 2004.

[6] S.-L. Wang and C.-Y. Wu, "Application of context-aware and personalized recommendation to implement an adaptive ubiquitous learning system," Expert Systems with Applications, vol. 38, no. 9, pp. 10831-10838, 2011.

[7] M. Mukhopadhyay, S. Pal, A. Nayyar, P. K. D. Pramanik, N. Dasgupta and P. Choudhury, "Facial Emotion Detection to Assess Learner's State of Mind in an Online Learning System," in 5th International Conference on Intelligent Information Technology (ICIIT 2020), Hanoi, Vietnam, 2020.

[8] C. Beckford and E. Mugisa, "A Tool for Learner-Centric Course Delivery in e-Learning," in ELearn: World Conference on E-Learning in Corporate, Government, Healthcare, and Higher Education, Orlando, Florida, 2010.

[9] A. K. Dey, B. Poddar, P. K. D. Pramanik, N. C. Debnath, S. Aljahdali and P. Choudhury, "Real-Time Learner Classification Using Cognitive Score," EPiC SeriesinComputing (Proceedings of 35th International Conference on Computers and Their Applications), vol. 69, pp. 264-276, 2020.

[10] R. C. Donnelly, "Embedding interaction within a blend of learner centric pedagogy and technology," World Journal on Educational Technology, vol. 1, pp. 6-29, 2009.

[11] S. Pal, P. K. D. Pramanik and P. Choudhury, "A Step Towards Smart Learning: Designing an Interactive Video-Based M-Learning System for Educational Institutes," International Journal of Web-Based Learning and Teaching Technologies, vol. 14, no. 4, pp. 26-48, 2019.

[12] P.-C. Sun, R. J. Tsai, G. Finger, Y.-Y. Chen and D. Yeh, "What drives a successful e-Learning? An empirical investigation of the critical factors influencing learner satisfaction," Computers \& Education, vol. 50, no. 4, pp. 1183-1202, 2008.

[13] R. H. Woods and J. D. Baker, "Interaction and Immediacy in Online Learning," International Review of Research in Open and Distance Learning, vol. 5, no. 2, pp. 1-13, 2004.

[14] R. M. Wallace, "Online Learning in Higher Education: a review of research on interactions among teachers and students," Education, Communication \& Information, vol. 3, no. 2, pp. 241-280, 2003.

[15] V. A. Nguyen, "An Online Question and Answering System for Support Teacher-Student Interaction in the Blended Learning Course," International Journal of Learning and Teaching, vol. 4, no. 3, pp. 178-184, 2018.

[16] I. Srba, M. Savic, M. Bielikova, M. Ivanovic and C. Pautasso, "Employing community question answering for online discussions in university courses: Students' perspective," Computers \& Education, vol. 135, pp. 75-90, 2019.

[17] A. M. N. Allam and M. H. Haggag, "The Question Answering Systems: A Survey," International Journal of Research and Reviews in Information Sciences, vol. 2, no. 3, pp. 1-13, 2012.

[18] E. Sneiders, "Automated FAQ answering with question-specific knowledge representation for web self-service," in Conference on Human System Interactions, Catania, Italy, 2009.

[19] E. Adamopoulou and L. Moussiades, "An Overview of Chatbot Technology," in Artificial Intelligence Applications and Innovations, IFIP Advances in Information and Communication 
Technology, Neos Marmaras, Greece, 2020.

[20] G. Sun, X. Liu, G. Cong, M. Zhou, Z. Xiong, J. Lee and C.-Y. Lin, "Detecting Erroneous Sentences using Automatically Mined Sequential Patterns," in Annual Meeting of the Association of Computational Linguistics, Prague, Czech Republic, 2007.

[21] M. Soni and J. S. Thakur, "A Systematic Review of Automated Grammar Checking in English Language," arXiv:1804.00540, pp. 1-23, 2018.

[22] E. Cambria and B. White, "Jumping NLP Curves: A Review of Natural Language Processing Research," IEEE Computational Intelligence Magazine, vol. 9, no. 2, pp. 48-57, 2014.

[23] C. Leacock, M. Chodorow, M. Gamon and J. Tetreault, Automated Grammatical Error Detection for Language Learners, USA: Morgan \& Claypool, 2010.

[24] K. Kowsari, K. J. Meimandi, M. Heidarysafa, S. Mendu, L. Barnes and D. Brown, "Text Classification Algorithms: A Survey," Information, vol. 10, no. 4, pp. 1-68, 2019.

[25] Y. Wang, Y. Wang, J. Liu and Z. Liu, "A Comprehensive Survey of Grammar Error Correction," arXiv:2005.06600 [cs.CL], pp. 1-35, 2020.

[26] S. Malik, M. Mandal and S. K. Bandyopadhyay, "Grammatical Error Checking and Polarity Determination of a Simple Sentence," Global Research and Development Journal for Engineering, vol. II, no. 7, pp. 142-146, 2017.

[27] T.-H. Chang, Y.-T. Sung, J.-F. Hong and J.-I. Chang, "KNGED: A Tool for Grammatical Error Diagnosis of Chinese Sentences," in International Conference on Computers in Education, Japan, 2014.

[28] L.-H. Lee, L.-P. Chang, K.-C. Lee, Y.-H. Tseng and H.-H. Chen, "Linguistic Rules Based Chinese Error Detection for Second Language Learning," in International Conference on Computers in Education, Denpasar Bali, Indonesia, 2013.

[29] A. Tezcan, V. Hoste and L. Macken, "Detecting Grammatical Errors in Machine Translation Output Using Dependency Parsing and Treebank Querying," in Conference of the European Association for Machine Translation, Riga, Latvia, 2016.

[30] B. R. Ganesh, D. Gupta and T. Sasikala, "Grammar Error Detection Tool for Medical Transcription Using Stop Words Parts-of-Speech Tags Ngram Based Model," in International Conference on Computational Intelligence and Informatics, Advances in Intelligent Systems and Computing, 2018.

[31] A. Schmaltz, Y. Kim, A. M. Rush and S. M. Shieber, "Sentence-Level Grammatical Error Identification as Sequence-to-Sequence Correction," in Workshop on Innovative Use of NLP for Building Educational Applications, San Diego, 2016.

[32] S. Islam, M. F. Sarkar, T. Hussain, M. M. Hasan, D. M. Farid and S. Shatabda, "Bangla Sentence Correction Using Deep Neural Network Based Sequence to Sequence Learning," in International Conference on Computer and Information Technology, Dhaka, 2018.

[33] G. Sun, G. Cong, X. Liu, C.-Y. Lin and M. Zhou, "Mining Sequential Patterns and Tree Patterns to Detect Erroneous Sentences," in Association for the Advancement of Artificial Intelligence, 2007.

[34] M. T. B. Othman, M. A. Al-Hagery and Y. M. El Hashemi, "Arabic Text Processing Model: Verbs Roots and Conjugation Automation," IEEE Access, vol. VIII, pp. 103913-103923, 2020.

[35] W. Zhao, L. Wang, K. Shen, R. Jia and J. Liu, "Improving Grammatical Error Correction via PreTraining a Copy-Augmented Architecture with Unlabeled Data," in Conference of the North American Chapter of the Association for Computational Linguistics: Human Language Technologies, 
Minneapolis, 2019.

[36] M. Rei and H. Yannakoudakis, "Auxiliary Objectives for Neural Error Detection Models," in Workshop on Innovative Use of NLP for Building Educational Applications, Copenhagen, 2017.

[37] H. Yannakoudakis, M. Rei, Ø. E. Andersen and Z. Yuan, "Neural Sequence-Labelling Models for Grammatical Error Correction," in Conference on Empirical Methods in Natural Language Processing, Copenhagen, 2017.

[38] T. Ge, F. Wei and M. Zhou, "Reaching Human-Level Performance in Automatic Grammatical Error Correction: An Empirical Study," ArXiv, Beijing, 2018.

[39] A. Sonawane, S. K. Vishwakarma, B. Srivastava and A. K. Singh, "Generating Inflectional Errors for Grammatical Error Correction in Hindi," in Conference of the Asia-Pacific Chapter of the Association for Computational Linguistics and the International Joint Conference on Natural Language Processing: Student Research Workshop, Suzhou, China, 2020.

[40] A. O. Maghraby, N. N. Khan, H. A. Ahmed, G. N. Brohi, H. F. Assouli and J. S. Melibari, "Tibyan Automated Arabic Correction Using Machine-Learning in Detecting Syntactical Mistakes," International Journal of Cognitive and Language Sciences, vol. 14, no. 6, pp. 402-406, 2020.

[41] Y. Wang, L. Wang, D. F. Wong, L. S. Chao, X. Zeng and Y. Lu, "Factored Statistical Machine Translation for Grammatical Error Correction," in Conference on Computational Natural Language Learning: Shared Task, Baltimore, 2014.

[42] M. Felice and T. Briscoe, "Towards a standard evaluation method for grammatical error detection and correction," in Conference of the North American Chapter of the Association for Computational Linguistics: Human Language Technologies, Denver, Colorado, 2015.

[43] "Design and Development of the Sentence - Based Collocation Recommendation with Error Detection for Academic Writing".

[44] L.-H. Lee, L.-C. Yu, K.-C. Lee, Y.-H. Tseng, L.-P. Chang and H.-H. Chen, "A Sentence Judgment System for Grammatical Error Detection," in International Conference on Computational Linguistics: System Demonstrations, Dublin, 2014.

[45] H. Cheng, H. Fang and M. Ostendorf, "Open-Domain Name Error Detection using a Multi-Task RNN," in Empirical Methods in Natural Language Processing, Lisbon, 2017.

[46] B. Zheng, W. Che, J. Guo and T. Liu, "Chinese Grammatical Error Diagnosis with Long Short-Term Memory Networks," in Workshop on Natural Language Processing Techniques for Educational Applications, Osaka, 2016.

[47] J.-F. Yeh, T.-W. Hsu and C.-K. Yeh, "Grammatical Error Detection Based on Machine Learning for Mandarin as Second Language Learning," in Workshop on Natural Language Processing Techniques for Educational Applications, Osaka, Japan, 2016.

[48] S.-M. Cheng, C.-H. Yu and H.-H. Chen, "Chinese Word Ordering Errors Detection and Correction for Non - Native Chinese Language Learner," in International Conference on Computational Linguistics: Technical Papers, Dublin, Ireland, 2014.

[49] H. Zan, Y. Han, H. Huang, Y. Yan, Y. Wang and Y. Han, "Chinese Grammatical Errors Diagnosis System Based on BERT at NLPTEA-2020 CGED Shared Task," in Workshop on Natural Language Processing Techniques for Educational Applications, Suzhou, China, 2020.

[50] N. Agarwal, M. A. Wani and P. Bours, "Lex-Pos Feature-Based Grammar Error Detection System for the English Language," Electronics, vol. IX, no. 10, pp. 1-17, 200. 
[51] M. Rei and H. Yannakoudakis, "Compositional Sequence Labeling Models for Error Detection in Learner Writing," in Annual Meeting of the Association for Computational Linguistics, Berlin, 2016.

[52] Y.-T. Shiue, H.-H. Huang and H.-H. Chen, "Detection of ChineseWord Usage Errors for Non-Native Chinese Learners with Bidirectional LSTM," in Annual Meeting of the Association for Computational Linguistics (Short Papers), Vancouver, Canada, 2017.

[53] C.-H. Yu and H.-H. Chen, "Detecting Word Ordering Errors in Chinese Sentences for Learning Chinese as a Foreign Language," in COLING 2012: Technical Papers, Mumbai, India, 2012.

[54] Y. Xiang, X. Wang, W. Han and Q. Hong, "Chinese Grammatical Error Diagnosis Using Ensemble Learning," in Workshop on Natural Language Processing Techniques for Educational Applications, Beijing, 2015.

[55] G. Ferraro, R. Nazar, M. A. Ramos and L. Wanner, "Towards advanced collocation error correction in Spanish learner corpora," Language Resources and Evaluation, vol. 48, p. 45-64, 2014.

[56] "Linguistic Rules Based Chinese Error Detection for Second Language Learning," in InternationalConference on, Bali, Indonesia, 2013.

[57] I. Szpektor, Y. Maarek and D. Pelleg, "When Relevance is Not Enough: Promoting Diversity and Freshness in Personalized Question Recommendation," in International Conference on World Wide Web, Rio de Janeiro, Brazil, 2013.

[58] J. Wang, L. Su, J. Chen and D. Jiang, "Question Recommendation Based on User Model in CQA," in Lecture Notes of the Institute for Computer Sciences, Social Informatics and Telecommunications Engineering, Guangzhou, China, 2017.

[59] M. Qu, G. Qiu, X. He, C. Zhang, H. Wu, J. Bu and C. Chen, "Probabilistic question recommendation for question answering communities," in International Conference on World Wide Web, Madrid, Spain, 2009.

[60] D. Yang, D. Adamson and C. P. Rosé, "Question recommendation with constraints for massive open online courses," in ACM Conference on Recommender systems, Foster City, Silicon Valley, 2014.

[61] H. Cai, C. Yan, A. Yin and X. Zhao, "Question Recommendation in Medical Community-Based Question Answering," in Neural Information Processing. Lecture Notes in Computer Science, Guangzhou, China, 2017.

[62] L. Fang, L. A. Tuan, S. C. Hui and L. Wu, "Personalized question recommendation for English grammar learning," Expert System, vol. 35, no. 2, pp. 1-15, 2017.

[63] S. Li and S. Manandhar, "Improving Question Recommendation by Exploiting Information Need," in Proceedings of the 49th Annual Meeting of the Association for Computational Linguistics: Human Language Technologies, Portland, Oregon, USA, 2011.

[64] T. Lei, H. Joshi, R. Barzilay, T. Jaakkola, K. Tymoshenko, A. Moschitti and L. Marquez, "Semisupervised Question Retrieval with Gated Convolutions," in Conference of the North American Chapter of the Association for Computational Linguistics: Human Language Technologies, San Diego, California, 2016.

[65] K. M. Giffels, C. J. Karle, W. G. O'Keeffe, K. T. Patel, D. D. Taieb and S. Yee, "Displaying quality of question being asked a question answering system". USA Patent US,10.713.571 B2, 2014.

[66] S. Joshi, R. S. Jadon and R. C. Jain, "Sequential Pattern Mining Using Formal language Tools," International Journal of Computer Science Issues, vol. IX, no. 5, pp. 2016-325, 2012.

[67] T. Slimani and A. Lazzez, "Sequential Mining: Patterns and Algorithms Analysis," International 
Journal of Computer \& Electronics Research, vol. 2, pp. 639-664, 20136.

[68] C. H. Mooney and J. F. Roddick, "Sequential Pattern Mining - Approaches and Algorithms," ACM Computing Surveys, vol. 45, no. 2, pp. 1-39, 2013.

[69] Q. Zhao and S. S. Bhowmick, "Sequential Pattern Mining: A Survey," CAIS, Nanyang Technological University, Singapore, 2003.

[70] A. Islam, E. Milios and V. Ke`selj, "Text Similarity Using Google Tri-grams," in Advances in Artificial Intelligence, L. Kosseim and D. Inkpen, Eds., Heidelberg, Berlin, Springer, 2012, pp. 312317.

[71] D. Jurafsky and J. H. Martin, Speech and Language Processing, 2nd ed., Pearson Education India, 2013.

[72] T. Brants, A. C. Popat, P. Xu, F. J. Och and J. Dean, "Large Language Models in Machine Translation," in Joint Conference on Empirical Methods in Natural Language Processing and Computational Natural Language Learning (EMNLP-CoNLL), Prague, Czech Republic, 2007.

[73] S. Sohangir and D. Wang, "Improved sqrt-cosine similarity measurement," Journal of Big Data, vol. 4, no. 25, pp. 1-13, 2017.

[74] A. A. Amer and H. I. Abdalla, "A set theory based similarity measure for text clustering and classification," Journal of Big Data, vol. 7, no. 74, pp. 1-43, 2020.

[75] G. Sidorov, A. Gelbukh, H. Gómez-Adorno and D. Pinto, "Soft Similarity and Soft Cosine Measure: Similarity of Features in Vector Space Model," Computacion y Sistemas , vol. 18, no. 3, pp. 1-14, 2014.

[76] M. Z. Hasan, S. Hossain, M. A. Rizvee and M. S. Rana, "Content based Document Classification using Soft Cosine Measure," International Journal of Advanced Computer Science and Applications, vol. 10, no. 4, pp. 522-528, 2019. 
Figure 1

Layout of the proposed work and the implementational environment

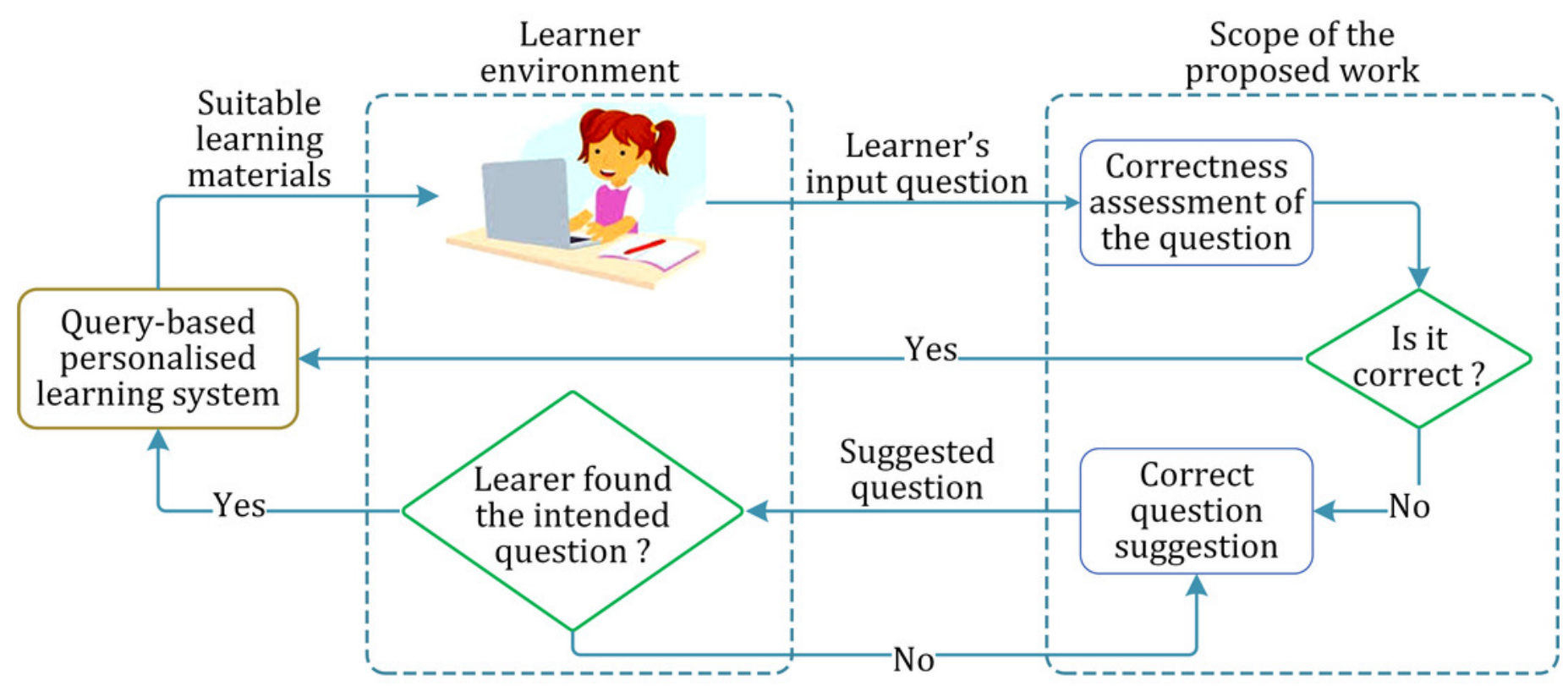


Figure 2

Steps for language model generation

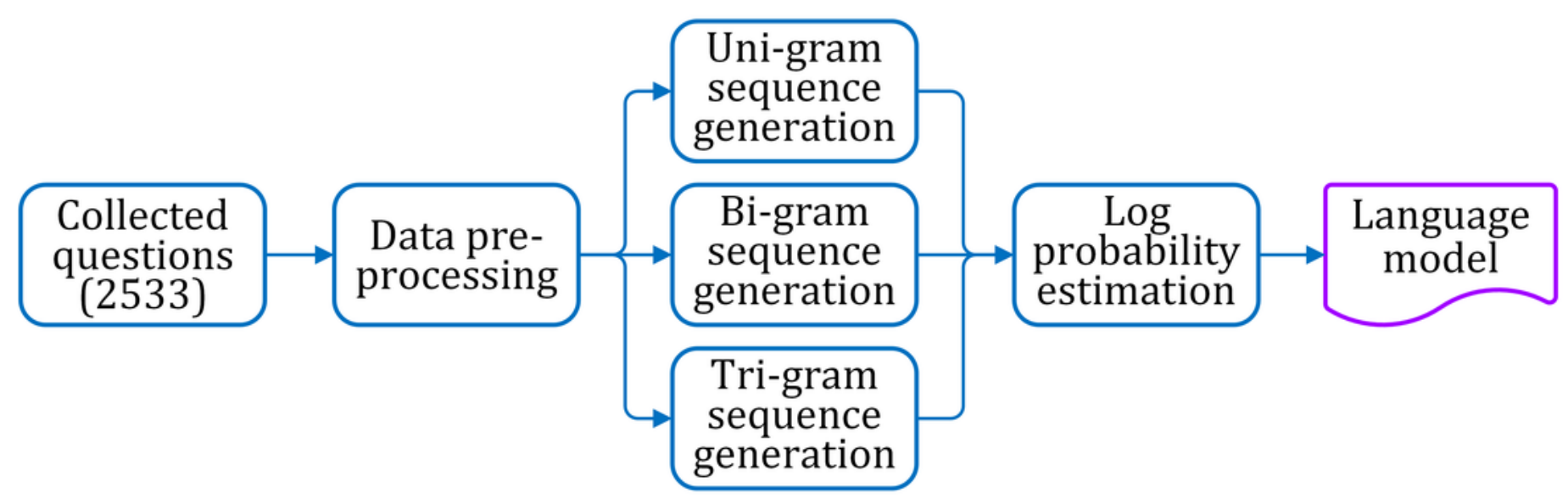




\section{Figure 3}

Figure 3. Typical steps for preprocessing a question

"what are the different types of operators used in Java?"
$\begin{gathered}\text { Stop words removal and } \\ \text { tokenizing the question }\end{gathered}$


Figure 4

Generating uni-gram, bi-gram and tri-gram sequences from a question

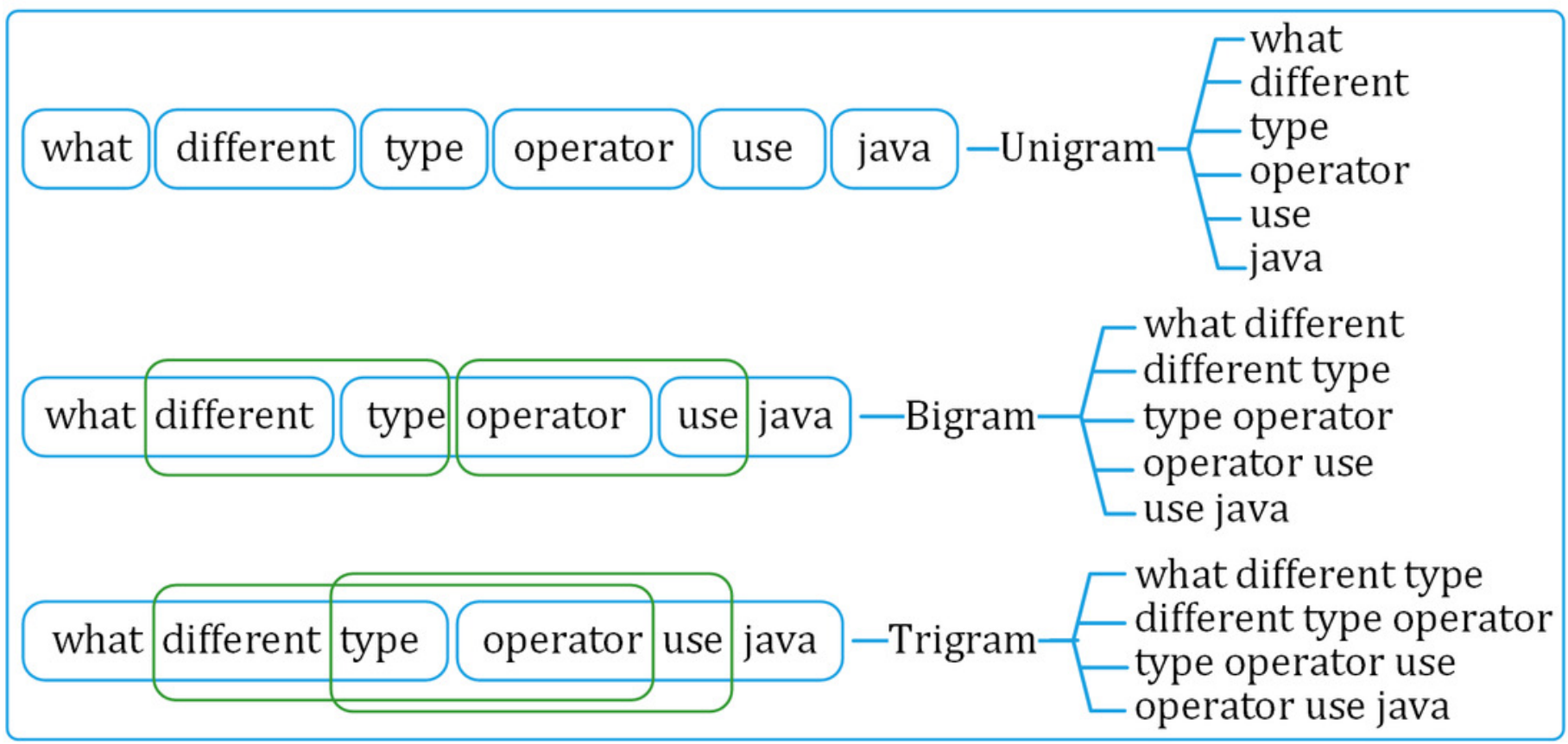


Figure 5

The flow diagram for identifying correct and incorrect questions

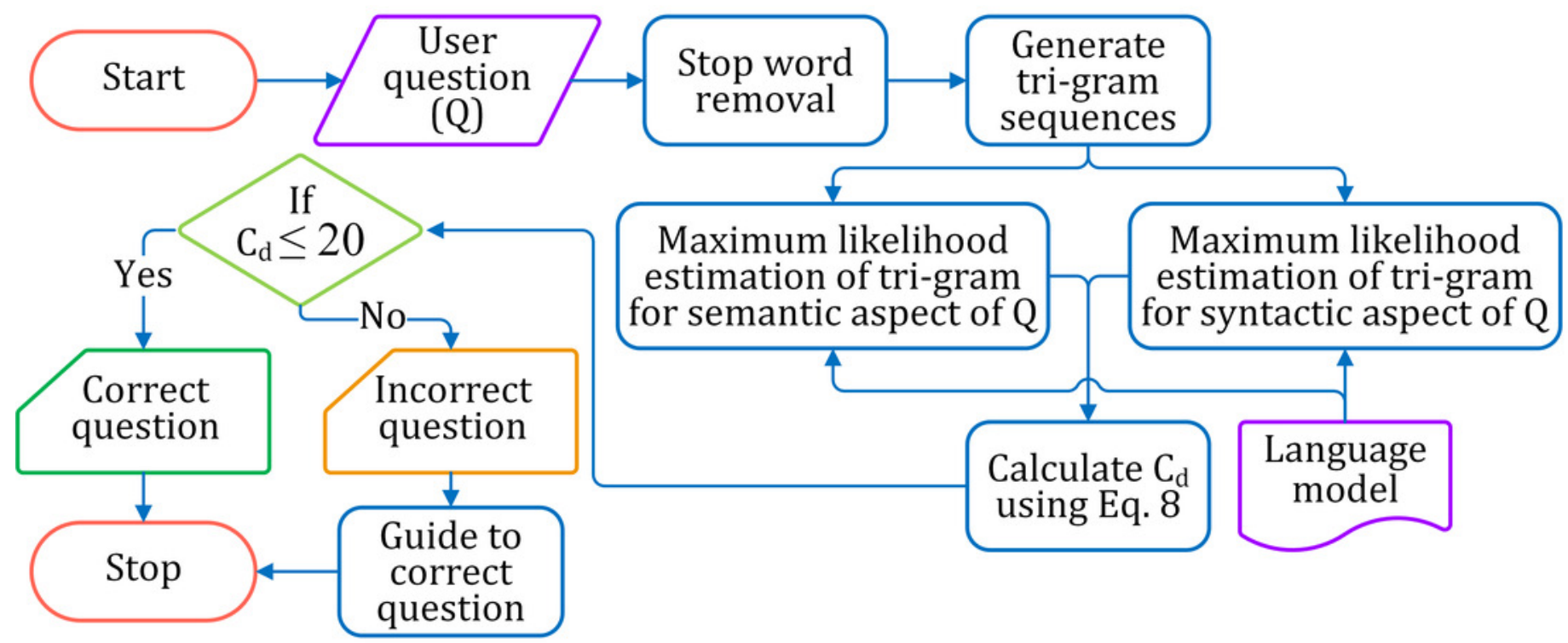


Figure 6

Accuracy comparison of the four n-gram approaches

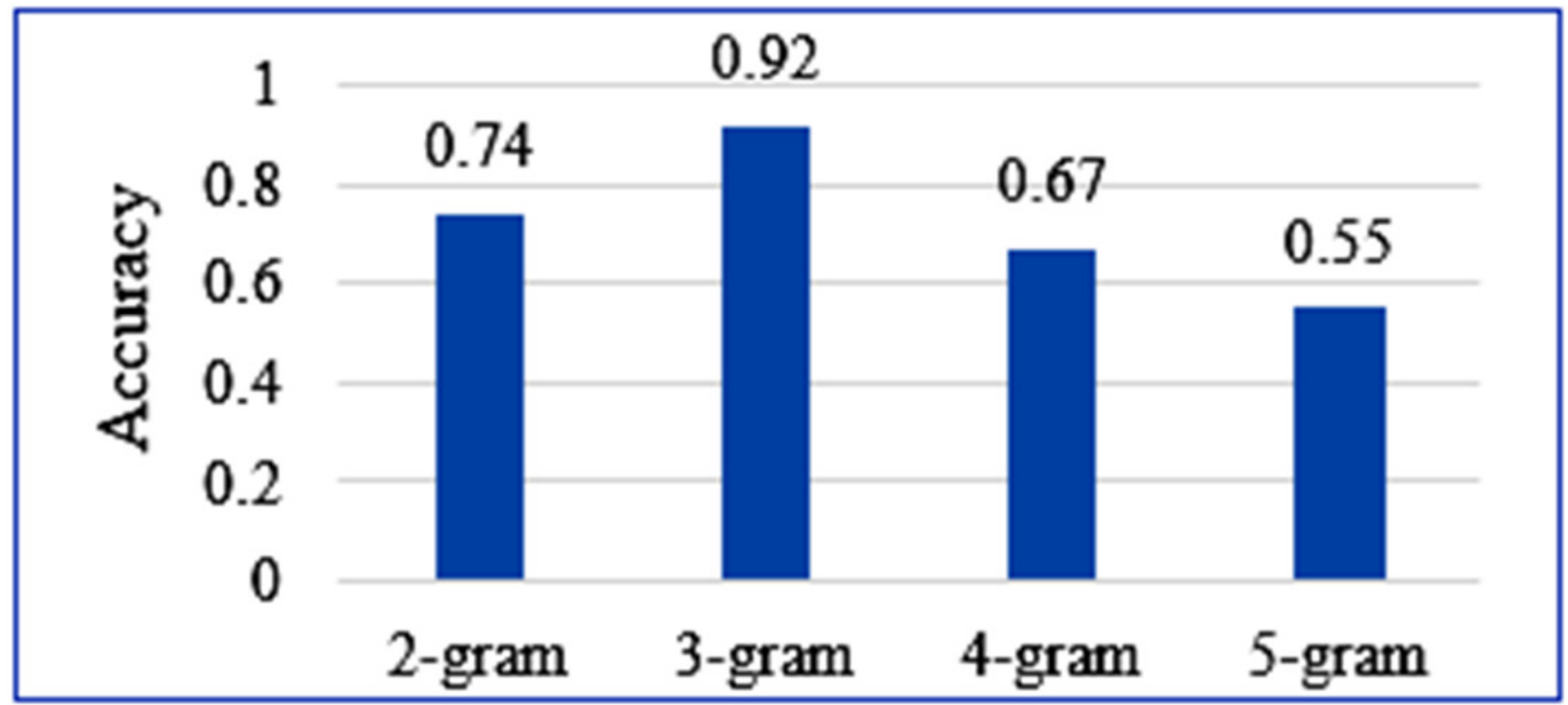




\section{Figure 7}

Typical mistakes made by the learner in a question

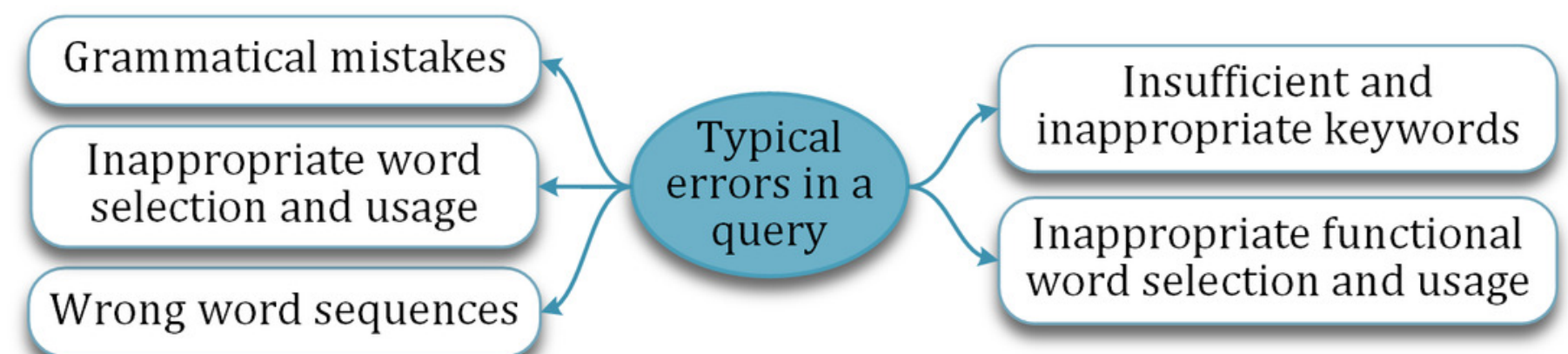


Figure 8

Returned similar questions belonging to different topics by Jaccard similarity

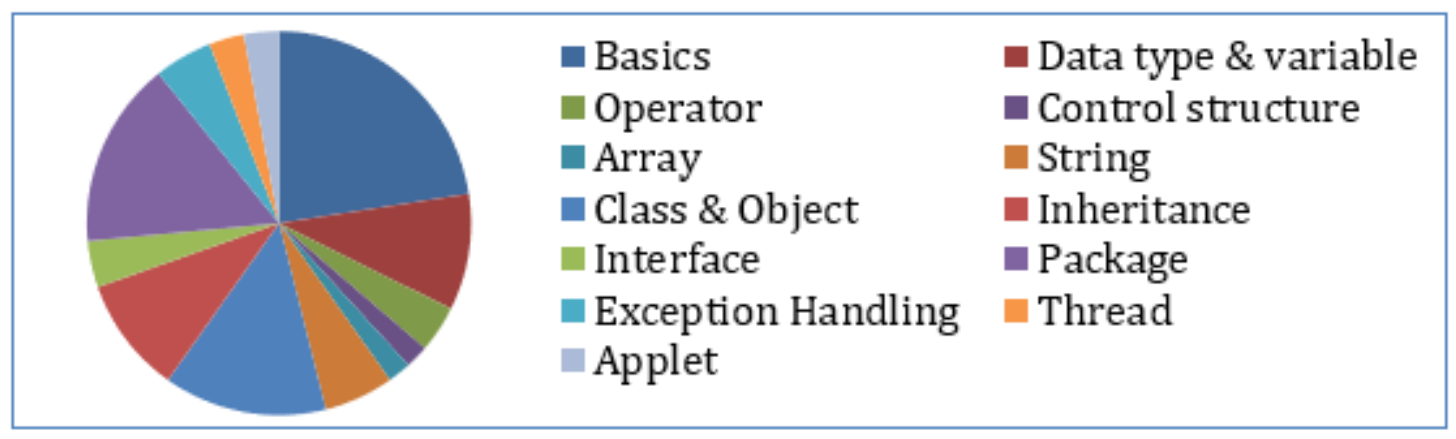


Figure 9

The proposed framework for correct question suggestion to the learner

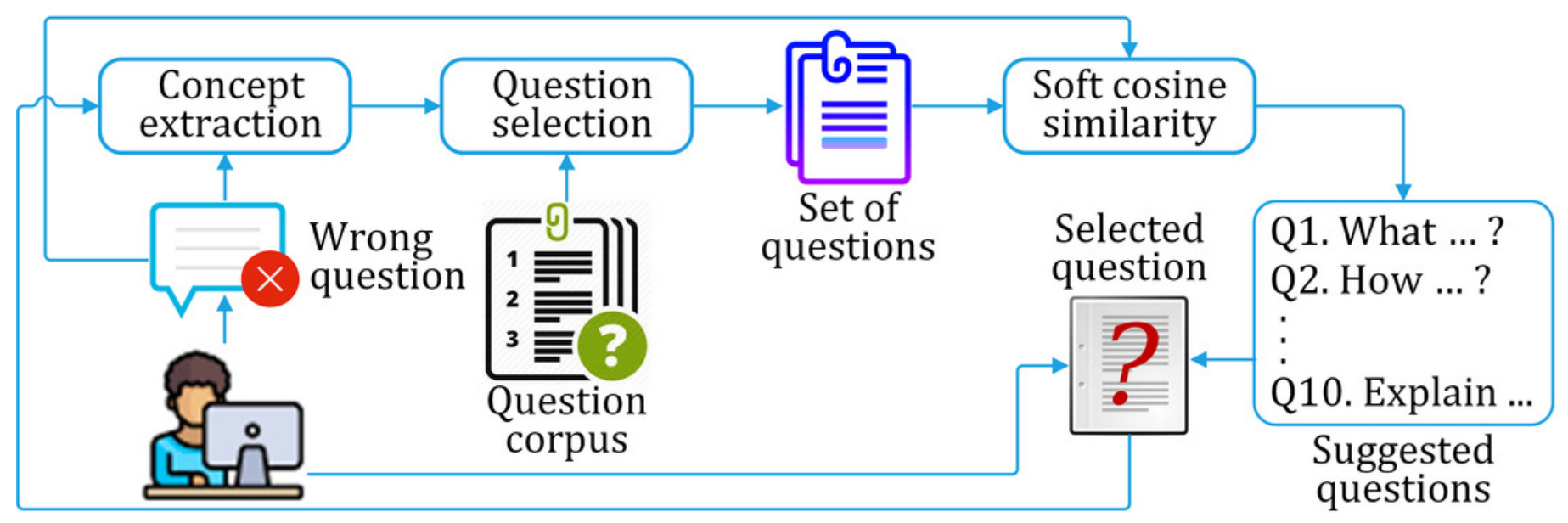




\section{Figure 10}

The flow diagram for suggesting correct questions to the learner

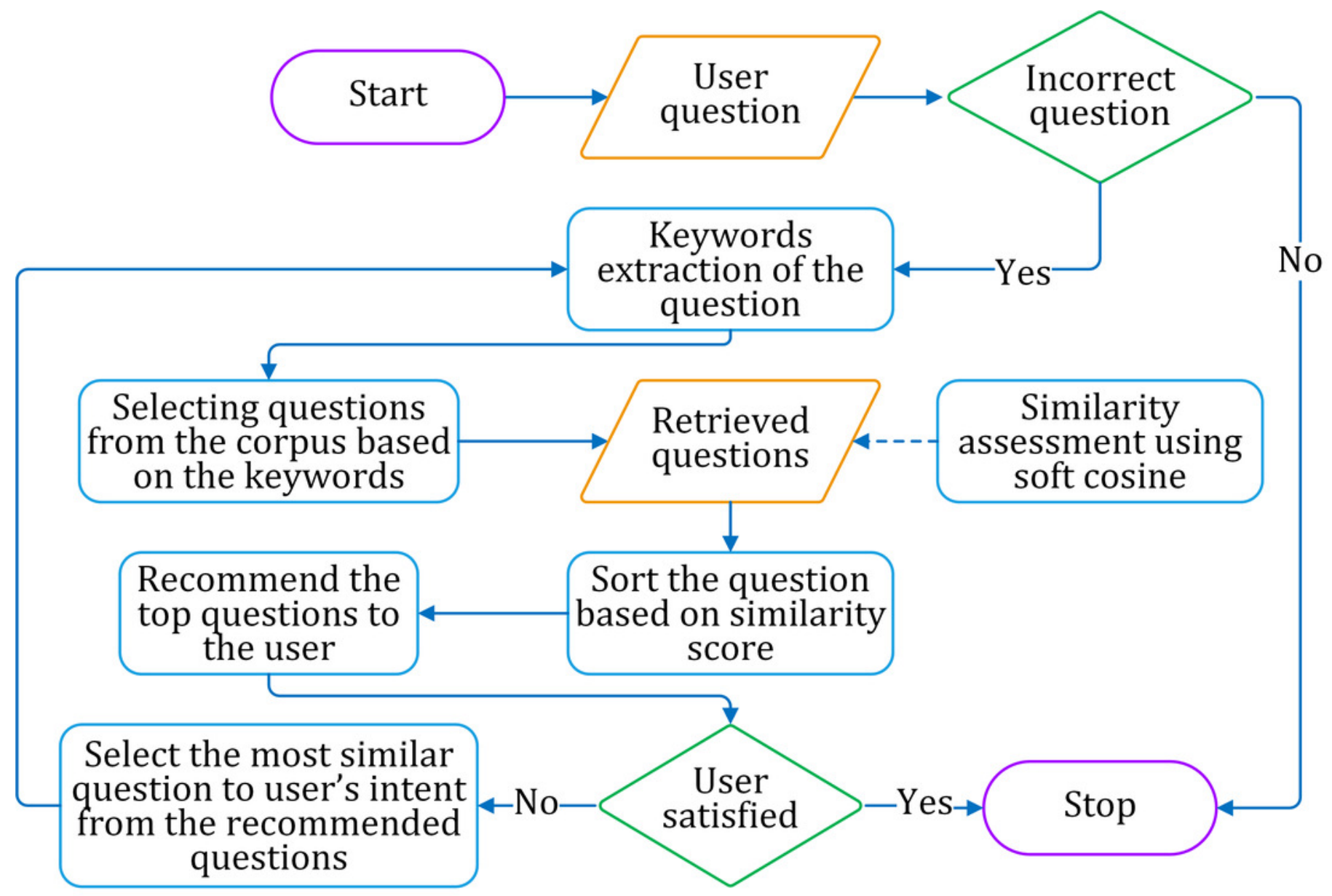


Figure 11

Comparison between cosine and soft cosine

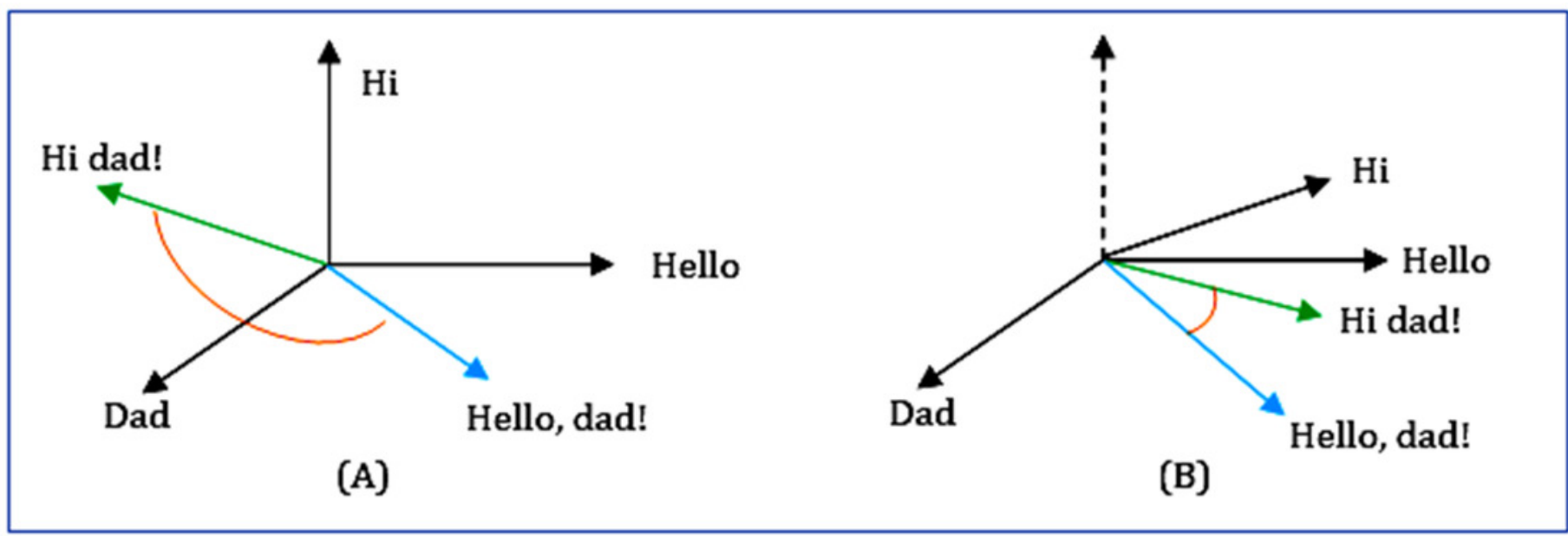


Figure 12

The web (client/server) model used to implement the proposed framework

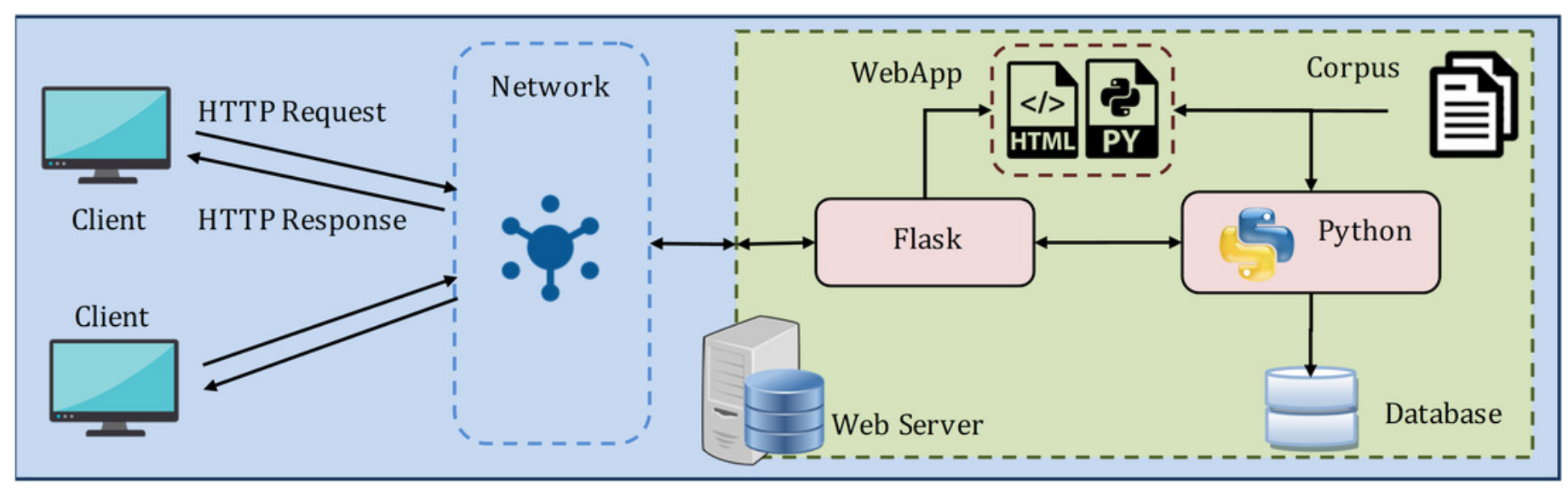




\title{
Figure 13
}

\author{
User interface for learner interaction
}

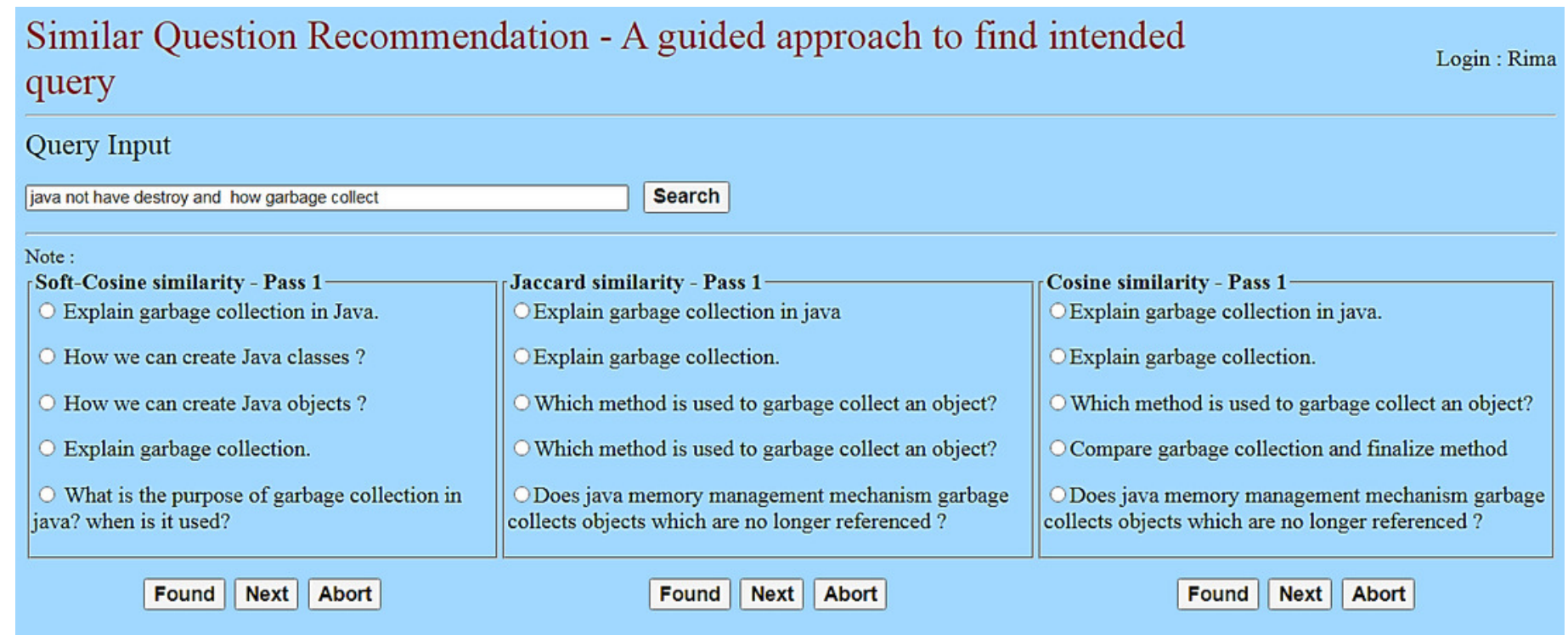




\section{Figure 14}

Comparing the correct question recommendation based on three similarity metrics

n Question found

ॠQuestion not found

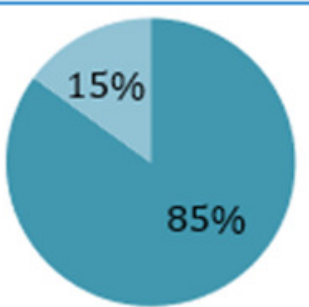

(A)

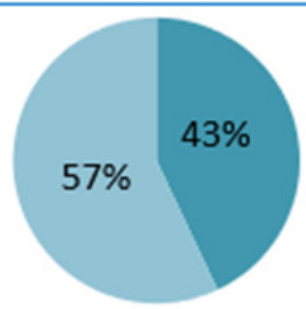

(B)

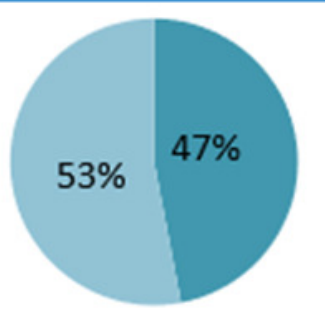

(C) 
Figure 15

Figure 15. Accuracy comparison for similar question recommendation of three similarity measures

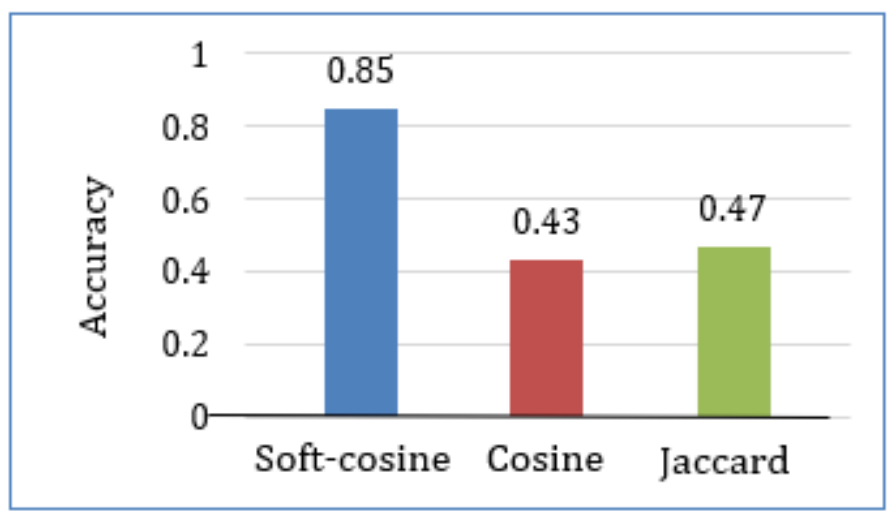




\section{Table $\mathbf{1}$ (on next page)}

Related work categorization based on error type and resolving approach 


\begin{tabular}{|c|c|c|c|c|}
\hline $\begin{array}{l}\text { Error } \\
\text { detection } \\
\text { approach }\end{array}$ & Working method & $\begin{array}{l}\text { Sentence } \\
\text { structure } \\
\text { error }\end{array}$ & $\begin{array}{l}\text { Syntax } \\
\text { error }\end{array}$ & $\begin{array}{l}\text { Semantic } \\
\text { error }\end{array}$ \\
\hline $\begin{array}{l}\text { Rule- } \\
\text { based } \\
\text { approach }\end{array}$ & $\begin{array}{l}\text { The rule-based approach calls for the } \\
\text { application of linguistic rule devised by a } \\
\text { linguistic expert for assessing the sentence to } \\
\text { find the errors. The rule-based approach } \\
\text { includes NLP techniques, tree parsing, etc. }\end{array}$ & $\begin{array}{l}26][27] \\
{[28][29]}\end{array}$ & $\begin{array}{l}26][27] \\
{[28][30]}\end{array}$ & [27] \\
\hline $\begin{array}{l}\text { Statistical } \\
\text { approach }\end{array}$ & $\begin{array}{l}\text { The statistical approach uses different } \\
\text { statistical and modelling techniques to know } \\
\text { more about the existing patterns to infer } \\
\text { knowledge. The statistical approach includes } \\
\text { techniques like machine learning, pattern } \\
\text { matching and mining. }\end{array}$ & $\begin{array}{ll}{[31]} & {[32]} \\
{[33]} & {[34]} \\
{[35]} & {[36]} \\
{[37]} & \end{array}$ & $\begin{array}{l}{[38][39]} \\
{[40][41]} \\
{[42][43]} \\
{[34][35]} \\
{[36][37]} \\
{[44][45]} \\
{[46][47]}\end{array}$ & $\begin{array}{ll}{[36]} & {[48]} \\
{[49]} & {[50]} \\
{[51]} & {[52]} \\
{[38]} & {[53]} \\
{[37]} & {[33]} \\
{[35]} & {[34]} \\
{[45]} & {[46]}\end{array}$ \\
\hline $\begin{array}{l}\text { Hybrid } \\
\text { approach }\end{array}$ & $\begin{array}{l}\text { Each of the approaches has shortcoming and } \\
\text { advantages in comparison to each for } \\
\text { detecting an error in the text. Since the } \\
\text { implicit working procedure for these } \\
\text { techniques is not competent enough to identify } \\
\text { the errors, thus the techniques are often } \\
\text { combined as a hybrid approach to overcome } \\
\text { the limitation of each other. }\end{array}$ & {$[54]$} & {$[55][56]$} & \\
\hline
\end{tabular}




\section{Table 2 (on next page)}

Differentiating characteristic feature of question in relation to textual sentence 


\begin{tabular}{|l|l|}
\hline Question & Other textual sentence \\
\hline Subject domains involved is important. & The subject domain is not important. \\
\hline $\begin{array}{l}\text { Presence and specific ordering of keywords } \\
\text { (semantic words) is significant. }\end{array}$ & $\begin{array}{l}\text { No significance is given to particular words } \\
\text { and their ordering and placement. }\end{array}$ \\
\hline $\begin{array}{l}\text { Verb/grammatical words which relates the } \\
\text { semantic words carries the entire meaning of } \\
\text { the question. }\end{array}$ & $\begin{array}{l}\text { The verb and other grammatical word play } \\
\text { important role to the whole sentence instead } \\
\text { limiting to specific words. }\end{array}$ \\
\hline
\end{tabular}




\section{Table 3(on next page)}

Uni-gram, bi-gram and tri-gram probabilities for a question 


\begin{tabular}{|l|l|l|l|l|l|}
\hline Unigram & $\begin{array}{l}\text { Unigram } \\
\text { probability }\end{array}$ & Bi-gram & $\begin{array}{l}\text { Bigram } \\
\text { probability }\end{array}$ & Tri-gram & $\begin{array}{l}\text { Tri-gram } \\
\text { probability }\end{array}$ \\
\hline what & 0.069 & what different & 0.034 & what different type & 0.294 \\
\hline different & 0.007 & different type & 0.157 & different type operator & 0.117 \\
\hline type & 0.008 & type operator & 0.023 & type operator use & 0.333 \\
\hline operator & 0.006 & operator use & 0.067 & operator use Java & 0.166 \\
\hline use & 0.008 & use Java & 0.024 & & \\
\hline Java & 0.042 & & & & \\
\hline
\end{tabular}

1 


\section{Table 4 (on next page)}

Performance measures of the proposed approach 
1

2

3

4

\begin{tabular}{|l|l|l|l|}
\hline Performance metric & Value & Performance measure & Value \\
\hline True positive & 282 & Accuracy & 0.9211 \\
\hline False positive & 18 & Precision & 0.9400 \\
\hline True negative & 302 & Recall & 0.8980 \\
\hline False negative & 32 & F1-Score & 0.9188 \\
\hline
\end{tabular}

5 


\section{Table 5 (on next page)}

Comparative results of the proposed approach and the solution given in [31] 


\begin{tabular}{|l|c|c|}
\hline & Proposed approach (\%) & Result of [31] (\%) \\
\hline Accuracy & 92.11 & 83.33 \\
\hline Precision & 94.00 & 94.11 \\
\hline Recall & 89.80 & 80.00 \\
\hline F1-Score & 91.88 & 86.48 \\
\hline
\end{tabular}

1 


\section{Table 6(on next page)}

Similar questions returned by Jaccard similarity for the learner question "what different are interface implement" 


\begin{tabular}{|c|c|c|c|}
\hline & Returned similar question & & Returned similar question \\
\hline 1 & What is the need for an interface? & 31 & What do you mean by interface? \\
\hline 2 & What are the properties of an interface? & 32 & $\begin{array}{l}\text { How interface is different from abstract } \\
\text { class? }\end{array}$ \\
\hline 3 & What is interface? & 33 & What are the different types of applet? \\
\hline 4 & $\begin{array}{l}\text { What are the methods under action } \\
\text { interface? }\end{array}$ & 34 & $\begin{array}{l}\text { Which methods of serializable } \\
\text { interface should I implement? }\end{array}$ \\
\hline 5 & $\begin{array}{l}\text { What are the methods under window } \\
\text { listener interface? }\end{array}$ & 35 & What is an externalizable interface? \\
\hline 6 & What is Java interface? & 36 & $\begin{array}{l}\text { What is vector? how is it different from } \\
\text { an array? }\end{array}$ \\
\hline 7 & What are the advantages of interfaces & 37 & $\begin{array}{l}\text { What are the methods under action } \\
\text { interface? }\end{array}$ \\
\hline 8 & What interfaces is needed & 38 & $\begin{array}{l}\text { What are the methods under window } \\
\text { listener interface? }\end{array}$ \\
\hline 9 & What is an interface? & 39 & What is Java interface? \\
\hline 10 & What are interfaces? & 40 & What are the advantages of interfaces? \\
\hline 11 & $\begin{array}{l}\text { What are constructors? how are they } \\
\text { different from methods? }\end{array}$ & 41 & $\begin{array}{l}\text { What are constructors? how are they } \\
\text { different from methods? }\end{array}$ \\
\hline 12 & How interface is different from class & 42 & $\begin{array}{l}\text { Is it necessary to implement all } \\
\text { methods in an interface? }\end{array}$ \\
\hline 13 & $\begin{array}{l}\text { What is an interface? how is it } \\
\text { implemented? }\end{array}$ & 43 & $\begin{array}{l}\text { If you do not implement all the } \\
\text { methods of an interface what specifier } \\
\text { should you use for the class? }\end{array}$ \\
\hline 14 & What are different modifiers? & 44 & $\begin{array}{l}\text { What is difference between interface } \\
\text { and class? }\end{array}$ \\
\hline 15 & $\begin{array}{l}\text { Is it necessary to implement all methods in } \\
\text { an interface? }\end{array}$ & 45 & $\begin{array}{l}\text { What is difference between package } \\
\text { and interface? }\end{array}$ \\
\hline 16 & $\begin{array}{l}\text { How interface is different from abstract } \\
\text { class? }\end{array}$ & 46 & What do you mean by interface? \\
\hline 17 & What are different comments? & 47 & What do you mean by interface? \\
\hline 18 & What are different modifiers? & 48 & $\begin{array}{l}\text { What is the nature of methods in } \\
\text { interface? }\end{array}$ \\
\hline 19 & $\begin{array}{l}\text { Is it necessary to implement all methods in } \\
\text { an interface? }\end{array}$ & 49 & $\begin{array}{l}\text { What do you know about the file name } \\
\text { filter interface? }\end{array}$ \\
\hline 20 & $\begin{array}{l}\text { How interface is different from abstract } \\
\text { class? }\end{array}$ & 50 & What is a nested interface? \\
\hline 21 & $\begin{array}{l}\text { If you do not implement all the methods of } \\
\text { an interface while implementing what } \\
\text { specifier should you use for the class? }\end{array}$ & 51 & $\begin{array}{l}\text { Which classes implements set } \\
\text { interface? }\end{array}$ \\
\hline
\end{tabular}




\begin{tabular}{|l|l|c|l|}
\hline 22 & $\begin{array}{l}\text { What must a class do to implement an } \\
\text { interface? }\end{array}$ & 52 & What is the interface of legacy? \\
\hline 23 & $\begin{array}{l}\text { What interface must an object implement } \\
\text { before it can be written to a stream as an } \\
\text { object? }\end{array}$ & 53 & $\begin{array}{l}\text { What is different between iterator and } \\
\text { listiterator? }\end{array}$ \\
\hline 24 & What is applet stub interface? & 54 & $\begin{array}{l}\text { What are different collection views } \\
\text { provided by map interface? }\end{array}$ \\
\hline 25 & How interface is different from a class. & 55 & $\begin{array}{l}\text { What is comparable and comparator } \\
\text { interface? }\end{array}$ \\
\hline 26 & What is an interface? & 56 & $\begin{array}{l}\text { What will happen if one of the } \\
\text { members in the class doesn't } \\
\text { implement serializable interface? }\end{array}$ \\
\hline 29 & What is interface? & 57 & What is serializable interface in Java? \\
\hline 30 & How interface is different from class? & 58 & What is externalizable interface? \\
\hline
\end{tabular}

1 


\section{Table 7 (on next page)}

Recommended list of question and their topic retrieved using Jaccard similarity for the incorrect input question "access modifier in Java" 


\begin{tabular}{|c|c|c|c|c|c|}
\hline & Recommended Question & Topic & & Recommended Question & Topic \\
\hline 1 & $\begin{array}{l}\text { What are the features of } \\
\text { java language? }\end{array}$ & Basics & 52 & $\begin{array}{l}\text { Briefly discuss the features of } \\
\text { java. }\end{array}$ & Basics \\
\hline 2 & $\begin{array}{l}\text { What is the need for java } \\
\text { language? }\end{array}$ & Basics & 53 & $\begin{array}{l}\text { What is jvm? Explain how java } \\
\text { works on a typical computer? }\end{array}$ & Basics \\
\hline 3 & $\begin{array}{l}\text { How java supports } \\
\text { platform independency? }\end{array}$ & Basics & 54 & $\begin{array}{l}\text { List out at least } 10 \text { difference } \\
\text { between java \& c++ }\end{array}$ & Basics \\
\hline 4 & $\begin{array}{l}\text { Why java is important to } \\
\text { internet? }\end{array}$ & Basics & 55 & $\begin{array}{l}\text { Explain, why java is the } \\
\text { language of choice among } \\
\text { network programmers }\end{array}$ & Basics \\
\hline 5 & $\begin{array}{l}\text { What are the types of } \\
\text { programs java can } \\
\text { handle? }\end{array}$ & Basics & 56 & $\begin{array}{l}\text { Write a java program to accept } \\
\text { two strings and check whether } \\
\text { string } 1 \text { is a sub string of string } 2 \\
\text { or not. }\end{array}$ & String \\
\hline 6 & $\begin{array}{l}\text { What are the advantages } \\
\text { of java language? }\end{array}$ & Basics & 57 & $\begin{array}{l}\text { Explain the relevance of static } \\
\text { variable and static methods in } \\
\text { java programming with an } \\
\text { example. }\end{array}$ & $\begin{array}{l}\text { Class \& } \\
\text { Object }\end{array}$ \\
\hline 7 & $\begin{array}{l}\text { Give the contents of java } \\
\text { environment (jdk). }\end{array}$ & Basics & 58 & $\begin{array}{l}\text { Describe the syntax of single } \\
\text { inheritance in java. }\end{array}$ & Inheritance \\
\hline 8 & $\begin{array}{l}\text { Give any } 4 \text { differences } \\
\text { between c and java. }\end{array}$ & Basics & 59 & $\begin{array}{l}\text { Name at least } 10 \text { java api class } \\
\text { you have used while } \\
\text { programming. }\end{array}$ & Package \\
\hline 9 & $\begin{array}{l}\text { Give any } 4 \text { differences } \\
\text { between } \mathrm{c}++ \text { and java. }\end{array}$ & Basics & 60 & Significance of interface in java? & Interface \\
\hline 10 & $\begin{array}{l}\text { What are the different } \\
\text { types of comment } \\
\text { symbols in java? }\end{array}$ & Basics & 61 & $\begin{array}{l}\text { Do class declaration include } \\
\text { both abstract and final } \\
\text { modifiers? }\end{array}$ & Inheritance \\
\hline 11 & $\begin{array}{l}\text { What are the data types } \\
\text { supported in java? }\end{array}$ & $\begin{array}{l}\text { Data type } \\
\& \text { variable }\end{array}$ & 62 & $\begin{array}{l}\text { Do java supports operator } \\
\text { overloading? }\end{array}$ & Operator \\
\hline 12 & $\begin{array}{l}\text { How is a constant defined } \\
\text { in java? }\end{array}$ & $\begin{array}{l}\text { Data type } \\
\& \text { variable }\end{array}$ & 63 & $\begin{array}{l}\text { Does java support multithreaded } \\
\text { programming? }\end{array}$ & Thread \\
\hline 13 & $\begin{array}{l}\text { What are the different } \\
\text { types of operators used in } \\
\text { java? }\end{array}$ & Operator & 64 & $\begin{array}{l}\text { Do java has a keyword called } \\
\text { finally? }\end{array}$ & $\begin{array}{l}\text { Exception } \\
\text { handling }\end{array}$ \\
\hline 14 & $\begin{array}{l}\text { What are the types of } \\
\text { variables java handles? }\end{array}$ & $\begin{array}{l}\text { Data type } \\
\& \text { variable }\end{array}$ & 65 & $\begin{array}{l}\text { Java does not provide } \\
\text { destructors? }\end{array}$ & $\begin{array}{l}\text { Class \& } \\
\text { Object }\end{array}$ \\
\hline 15 & $\begin{array}{l}\text { How is object destruction } \\
\text { done in java? }\end{array}$ & $\begin{array}{l}\text { Class \& } \\
\text { Object }\end{array}$ & 66 & $\begin{array}{l}\text { Do the vector class is contained } \\
\text { in java.util package? }\end{array}$ & Package \\
\hline 16 & What is a string in java? & String & 67 & Does private modifier can be & Inheritance \\
\hline
\end{tabular}




\begin{tabular}{|c|c|c|c|c|c|}
\hline & & & & $\begin{array}{l}\text { invoked only by code in a } \\
\text { subclass? }\end{array}$ & \\
\hline 17 & $\begin{array}{l}\text { What are the different } \\
\text { access specifiers } \\
\text { available in java? }\end{array}$ & Package & 68 & $\begin{array}{l}\text { Does all files are included in the } \\
\text { java.io package? }\end{array}$ & Package \\
\hline 18 & $\begin{array}{l}\text { What is the default access } \\
\text { specifier in java? }\end{array}$ & Package & 69 & $\begin{array}{l}\text { Java supports multiple } \\
\text { inheritance? }\end{array}$ & Interface \\
\hline 19 & $\begin{array}{l}\text { What is a package in } \\
\text { java? }\end{array}$ & Package & 70 & $\begin{array}{l}\text { Do java.applet is used for } \\
\text { creating and implementing } \\
\text { applets? }\end{array}$ & Applet \\
\hline 20 & $\begin{array}{l}\text { Name some java api } \\
\text { packages }\end{array}$ & Package & 71 & $\begin{array}{l}\text { How applets are programs that } \\
\text { executes within a java enabled } \\
\text { web browser? }\end{array}$ & Applet \\
\hline 21 & $\begin{array}{l}\text { Explain the features of } \\
\text { java language. }\end{array}$ & Basics & 72 & Is java a high-level language? & Basics \\
\hline 22 & $\begin{array}{l}\text { Compare and contrast } \\
\text { java with c. }\end{array}$ & Basics & 73 & $\begin{array}{l}\text { What are byte codes and java } \\
\text { virtual machine? }\end{array}$ & Basics \\
\hline 23 & $\begin{array}{l}\text { Compare and contrast } \\
\text { java with } \mathrm{c}++ \text {. }\end{array}$ & Basics & 74 & Explain about java variables. & $\begin{array}{l}\text { Data type } \\
\text { \& variable }\end{array}$ \\
\hline 24 & $\begin{array}{l}\text { Discuss in detail the } \\
\text { access specifiers } \\
\text { available in java. }\end{array}$ & Package & 75 & $\begin{array}{l}\text { Differentiate between java } \\
\text { applications and java applets. }\end{array}$ & Applet \\
\hline 25 & $\begin{array}{l}\text { Explain the different } \\
\text { methods in } \\
\text { java.util.arrays class with } \\
\text { example. }\end{array}$ & Array & 76 & What is a thread in java? & Thread \\
\hline 26 & $\begin{array}{l}\text { How multiple inheritance } \\
\text { is achieved in java? }\end{array}$ & Package & 77 & $\begin{array}{l}\text { Explain the meaning of public } \\
\text { static and void modifiers for the } \\
\text { main() method in a java } \\
\text { program. }\end{array}$ & $\begin{array}{l}\text { Class \& } \\
\text { Object }\end{array}$ \\
\hline 27 & $\begin{array}{l}\text { How does java handle } \\
\text { integer overflows and } \\
\text { underflows? }\end{array}$ & $\begin{array}{l}\text { Data type } \\
\& \text { variable }\end{array}$ & 78 & $\begin{array}{l}\text { Explain about inheritance in } \\
\text { java. }\end{array}$ & Inheritance \\
\hline 28 & $\begin{array}{l}\text { How java handle } \\
\text { overflows and } \\
\text { underflows? }\end{array}$ & $\begin{array}{l}\text { Data type } \\
\& \text { variable }\end{array}$ & 79 & $\begin{array}{l}\text { Explain about polymorphism in } \\
\text { java. }\end{array}$ & Inheritance \\
\hline 29 & $\begin{array}{l}\text { What are the threads will } \\
\text { start when you start the } \\
\text { java program? }\end{array}$ & Thread & 80 & $\begin{array}{l}\text { Explain the structure of a java } \\
\text { program. }\end{array}$ & Basics \\
\hline 30 & What is java math class? & Package & 81 & What are the steps for & Basics \\
\hline
\end{tabular}




\begin{tabular}{|c|c|c|c|c|c|}
\hline & $\begin{array}{l}\text { List } 10 \text { method with } \\
\text { syntax. }\end{array}$ & & & implementing a java program? & \\
\hline 31 & Explain java data types? & $\begin{array}{l}\text { Data type } \\
\& \text { variable }\end{array}$ & 82 & Explain java data types. & $\begin{array}{l}\text { Data type } \\
\& \text { variable }\end{array}$ \\
\hline 32 & What is java array? & Array & 83 & $\begin{array}{l}\text { Write the different operators in } \\
\text { java. }\end{array}$ & Operator \\
\hline 33 & $\begin{array}{l}\text { Write short notes on java } \\
\text { method with syntax and } \\
\text { example. }\end{array}$ & $\begin{array}{l}\text { Class \& } \\
\text { Object }\end{array}$ & 84 & $\begin{array}{l}\text { What are the control statements } \\
\text { available in java? }\end{array}$ & $\begin{array}{l}\text { Control } \\
\text { structure }\end{array}$ \\
\hline 34 & $\begin{array}{l}\text { What is java variable? } \\
\text { Explain the different } \\
\text { types of variable. }\end{array}$ & $\begin{array}{l}\text { Data type } \\
\& \text { variable }\end{array}$ & 85 & $\begin{array}{l}\text { What are the looping statements } \\
\text { available in java? }\end{array}$ & $\begin{array}{l}\text { Control } \\
\text { structure }\end{array}$ \\
\hline 35 & $\begin{array}{l}\text { Explain garbage } \\
\text { collection in java. }\end{array}$ & $\begin{array}{l}\text { Class \& } \\
\text { Object }\end{array}$ & 86 & $\begin{array}{l}\text { What are the different string } \\
\text { methods available in java? }\end{array}$ & String \\
\hline 36 & $\begin{array}{l}\text { There is no destructor in } \\
\text { java, Justify. }\end{array}$ & $\begin{array}{l}\text { Class \& } \\
\text { Object }\end{array}$ & 87 & $\begin{array}{l}\text { What are the different string } \\
\text { buffer methods available in } \\
\text { java? }\end{array}$ & String \\
\hline 37 & What are java classes? & $\begin{array}{l}\text { Class \& } \\
\text { Object }\end{array}$ & 88 & $\begin{array}{l}\text { What is the use of this keyword } \\
\text { in java? }\end{array}$ & $\begin{array}{l}\text { Class \& } \\
\text { Object }\end{array}$ \\
\hline 38 & $\begin{array}{l}\text { How we can create java } \\
\text { classes. }\end{array}$ & $\begin{array}{l}\text { Class \& } \\
\text { Object }\end{array}$ & 89 & $\begin{array}{l}\text { What is the use of super } \\
\text { keyword in java? }\end{array}$ & Inheritance \\
\hline 39 & $\begin{array}{l}\text { How we can create java } \\
\text { objects? }\end{array}$ & $\begin{array}{l}\text { Class \& } \\
\text { Object }\end{array}$ & 90 & $\begin{array}{l}\text { What is the use of finally } \\
\text { keywords in java? }\end{array}$ & $\begin{array}{l}\text { Exception } \\
\text { Handling }\end{array}$ \\
\hline 40 & What is java string? & String & 91 & $\begin{array}{l}\text { Explain about different class } \\
\text { modifiers. }\end{array}$ & Package \\
\hline 41 & $\begin{array}{l}\text { How we can initialize and } \\
\text { create java string explains } \\
\text { with } 10 \text { methods? }\end{array}$ & String & 92 & $\begin{array}{l}\text { Explain about different } \\
\text { constructor modifiers. }\end{array}$ & $\begin{array}{l}\text { Class \& } \\
\text { Object }\end{array}$ \\
\hline 42 & $\begin{array}{l}\text { Explain java character } \\
\text { class with suitable } \\
\text { example and methods }\end{array}$ & Package & 93 & $\begin{array}{l}\text { Explain the use of method } \\
\text { modifiers. }\end{array}$ & Inheritance \\
\hline 43 & $\begin{array}{l}\text { What is inheritance in } \\
\text { java? Explain all its type } \\
\text { with example. }\end{array}$ & $\begin{array}{l}\text { Inheri- } \\
\text { tance }\end{array}$ & 94 & $\begin{array}{l}\text { Write short notes on different } \\
\text { java api packages. }\end{array}$ & Package \\
\hline 44 & $\begin{array}{l}\text { Explain interface in java. } \\
\text { How do interfaces } \\
\text { support polymorphism? }\end{array}$ & Interface & 95 & $\begin{array}{l}\text { Write short notes on different } \\
\text { exception types available in } \\
\text { java. }\end{array}$ & $\begin{array}{l}\text { Exception } \\
\text { handling }\end{array}$ \\
\hline 45 & $\begin{array}{l}\text { Explain package in java. } \\
\text { List out all packages with } \\
\text { short description. }\end{array}$ & Package & 96 & $\begin{array}{l}\text { Explain about catch, throw and } \\
\text { try statement in java. }\end{array}$ & $\begin{array}{l}\text { Exception } \\
\text { handling }\end{array}$ \\
\hline
\end{tabular}




\begin{tabular}{|l|l|l|l|l|l|}
\hline 46 & What is java interface. & Interface & 97 & $\begin{array}{l}\text { Why does java not support } \\
\text { destructors and how does the } \\
\text { finalize method will help in } \\
\text { garbage collections? }\end{array}$ & $\begin{array}{l}\text { Class \& } \\
\text { Object }\end{array}$ \\
\hline 47 & $\begin{array}{l}\text { Explain exception } \\
\text { handling in java. }\end{array}$ & $\begin{array}{l}\text { Exception } \\
\text { handling }\end{array}$ & 98 & $\begin{array}{l}\text { Write short notes on access } \\
\text { specifiers and modifiers in java. }\end{array}$ & Package \\
\hline 48 & $\begin{array}{l}\text { What led to the creation } \\
\text { of java? }\end{array}$ & Basics & 99 & $\begin{array}{l}\text { Discuss the working and } \\
\text { meaning of the "static" modifier } \\
\text { with suitable examples. }\end{array}$ & $\begin{array}{l}\text { Class \& } \\
\text { Object }\end{array}$ \\
\hline 49 & $\begin{array}{l}\text { What are the steps to be } \\
\text { followed for executing a } \\
\text { java program? }\end{array}$ & Basics & 100 & $\begin{array}{l}\text { Explain in detail as how } \\
\text { inheritance is supported in java } \\
\text { with necessary example. }\end{array}$ & Inheritance \\
\hline 50 & $\begin{array}{l}\text { Explain the data types } \\
\text { available in java }\end{array}$ & $\begin{array}{l}\text { Data type } \\
\& \text { variable }\end{array}$ & 101 & $\begin{array}{l}\text { Explain in detail as how } \\
\text { polymorphism is supported in } \\
\text { java with necessary example }\end{array}$ & Inheritance \\
\hline 51 & $\begin{array}{l}\text { What are the different } \\
\text { types of operators in } \\
\text { java? }\end{array}$ & Operator & 102 & $\begin{array}{l}\text { What are the java apis used for } \\
\text { package? }\end{array}$ & Package \\
\hline
\end{tabular}

1 


\section{Table 8 (on next page)}

Similarity recommendation against learner questions 


\begin{tabular}{|c|c|c|c|c|c|}
\hline \multirow{2}{*}{ User Input } & \multirow{2}{*}{ 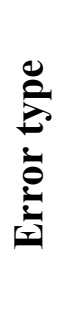 } & \multirow{2}{*}{ Intended question } & 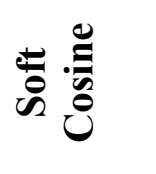 & 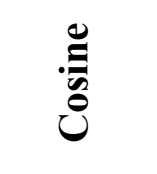 & 节 \\
\hline & & & $\begin{array}{l}\text { No. of } \\
\text { Pass } \\
\text { (Score) }\end{array}$ & $\begin{array}{l}\text { No. of } \\
\text { Pass } \\
\text { (Score) }\end{array}$ & $\begin{array}{l}\text { No. of } \\
\text { Pass } \\
\text { (Score) }\end{array}$ \\
\hline what difference interface & $\mathrm{I}_{\mathrm{S}}$ & $\begin{array}{l}\text { What is the difference between } \\
\text { abstract class and interface? }\end{array}$ & $1(0.63)$ & $1(0.51)$ & $\mathrm{NF}$ \\
\hline $\begin{array}{l}\text { define method in } \\
\text { subclass with same } \\
\text { name }\end{array}$ & $\mathrm{I}_{\mathrm{S}}$ & $\begin{array}{l}\text { It is not possible to define a } \\
\text { method in the subclass that has } \\
\text { the same name same arguments } \\
\text { and the same return type. }\end{array}$ & $1(0.66)$ & $1(0.5)$ & NF \\
\hline $\begin{array}{l}\text { java not have destroy } \\
\text { and how garbage collect }\end{array}$ & $\mathrm{E}_{\mathrm{G}}$ & $\begin{array}{l}\text { Why does java not support } \\
\text { destructors and how does the } \\
\text { finalize method will help in } \\
\text { garbage collections? }\end{array}$ & $2(0.61)$ & NF & NF \\
\hline how to overload & $\mathrm{I}_{\mathrm{S}}$ & $\begin{array}{l}\text { What is method overloading? } \\
\text { Explain with example. }\end{array}$ & $2(0.6)$ & NF & NF \\
\hline why main public & $\mathrm{I}_{\mathrm{S}}$ & $\begin{array}{l}\text { Why is main method assigned } \\
\text { as static? }\end{array}$ & $2(0.75)$ & NF & $2(0.6)$ \\
\hline object stored reach & $\mathrm{E}_{\mathrm{G}}$ & $\begin{array}{l}\text { When an object is stored are all } \\
\text { of the objects that are } \\
\text { reachable from that object } \\
\text { stored as well? }\end{array}$ & $1(0.91)$ & NF & NF \\
\hline $\begin{array}{l}\text { what mechanism used } \\
\text { for a single thread at a } \\
\text { time }\end{array}$ & $\mathrm{E}_{\mathrm{G}}$ & $\begin{array}{l}\text { What is the mechanism defined } \\
\text { by java for the resources to be } \\
\text { used by only one thread at a } \\
\text { time? }\end{array}$ & $1(0.59)$ & $2(0.41)$ & $1(0.36)$ \\
\hline applets talk on web page & $\mathrm{I}_{\mathrm{S}}$ & $\begin{array}{l}\text { How can I arrange for different } \\
\text { applets on a web page to } \\
\text { communicate with each other? }\end{array}$ & $1(0.57)$ & NF & $1(0.42)$ \\
\hline show try catch throw & $\mathrm{I}_{\mathrm{S}}$ & $\begin{array}{l}\text { Write a java program which } \\
\text { illustrates the try catch throw } \\
\text { and throws and finally blocks. }\end{array}$ & $1(0.64)$ & NF & NF \\
\hline $\begin{array}{l}\text { why thread } \\
\text { synchronization needed }\end{array}$ & $\mathrm{I}_{\mathrm{S}}$ & $\begin{array}{l}\text { Describe the need of thread } \\
\text { synchronization. How is it } \\
\text { achieved in Java } \\
\text { programming? Explain with a } \\
\text { suitable program. }\end{array}$ & $2(0.51)$ & $2(0.33)$ & $2(0.37)$ \\
\hline access modifiers in java & $\mathrm{I}_{\mathrm{S}}$ & $\begin{array}{l}\text { Explain access modifiers and } \\
\text { access controls at class and } \\
\text { package level in Java. }\end{array}$ & $1(0.58)$ & NF & $1(0.25)$ \\
\hline $\begin{array}{l}\text { difference between } \\
\text { exceptions }\end{array}$ & $\mathrm{I}_{\mathrm{S}}$ & $\begin{array}{l}\text { What is difference between } \\
\text { user defined exceptions and } \\
\text { system exceptions? }\end{array}$ & $\mathrm{NF}$ & $1(0.37)$ & NF \\
\hline
\end{tabular}




\begin{tabular}{|c|c|c|c|c|c|}
\hline $\begin{array}{l}\text { inbuilt exceptions in } \\
\text { class }\end{array}$ & $\mathrm{I}_{\mathrm{S}}$ & $\begin{array}{l}\text { Explain with example any } \\
\text { three inbuilt exceptions and } \\
\text { any three inbuilt methods of } \\
\text { exception provided by } \\
\text { exception class. }\end{array}$ & $1(0.51)$ & $\mathrm{NF}$ & $\mathrm{NF}$ \\
\hline $\begin{array}{l}\text { class extends another } \\
\text { class how to handle } \\
\text { exception }\end{array}$ & $\mathrm{I}_{\mathrm{S}}$ & $\begin{array}{l}\text { If my class already extends } \\
\text { from some other class then } \\
\text { what should I do, if I want an } \\
\text { instance of my class to be } \\
\text { thrown as an exception object? }\end{array}$ & $1(0.72)$ & $\mathrm{NF}$ & NF \\
\hline $\begin{array}{l}\text { if we do not initialize } \\
\text { variables }\end{array}$ & $\mathrm{I}_{\mathrm{S}}$ & $\begin{array}{l}\text { What happens if you do not } \\
\text { initialize an instance variable } \\
\text { of any of the primitive types in } \\
\text { Java? }\end{array}$ & NF & $\mathrm{NF}$ & $\mathrm{NF}$ \\
\hline $\begin{array}{l}\text { Inheritance hierarchy in } \\
\text { AWT. }\end{array}$ & $\mathrm{E}_{\mathrm{G}}$ & $\begin{array}{l}\text { Draw the inheritance hierarchy } \\
\text { for the frame and component } \\
\text { classes in AWT. }\end{array}$ & $1(0.53)$ & $1(0.37)$ & NF \\
\hline $\begin{array}{l}\text { which specifier to use } \\
\text { while all not interface } \\
\text { implement }\end{array}$ & $\mathrm{E}_{\mathrm{G}}$ & $\begin{array}{l}\text { If you do not implement all the } \\
\text { methods of an interface while } \\
\text { implementing what specifier } \\
\text { should you use for the class? }\end{array}$ & $1(0.75)$ & $\mathrm{NF}$ & $1(0.5)$ \\
\hline $\begin{array}{l}\text { first value of array } \\
\text { elements }\end{array}$ & $\mathrm{I}_{\mathrm{S}}$ & $\begin{array}{l}\text { What will be the default values } \\
\text { of all the elements of an array } \\
\text { that are defined as an instance } \\
\text { variable? }\end{array}$ & $1(0.56)$ & $\mathrm{NF}$ & $1(0.33)$ \\
\hline $\begin{array}{l}\text { difference between two } \\
\text { types programming } \\
\text { language }\end{array}$ & $\mathrm{I}_{\mathrm{S}}$ & $\begin{array}{l}\text { What is the difference between } \\
\text { an object-oriented } \\
\text { programming language and } \\
\text { object-based programming } \\
\text { language? }\end{array}$ & $1(0.68)$ & $1(0.41)$ & $\mathrm{NF}$ \\
\hline $\begin{array}{l}\text { we change throws when } \\
\text { override }\end{array}$ & $\mathrm{E}_{\mathrm{G}}$ & $\begin{array}{l}\text { Can we modify the throws } \\
\text { clause of the superclass method } \\
\text { while overriding it in the } \\
\text { subclass? }\end{array}$ & $2(0.55)$ & $\mathrm{NF}$ & $\mathrm{NF}$ \\
\hline $\begin{array}{l}\text { name of object with own } \\
\text { lifecycle }\end{array}$ & $\mathrm{I}_{\mathrm{S}}$ & $\begin{array}{l}\text { What is it called where object } \\
\text { has its own lifecycle and child } \\
\text { object cannot belong to another } \\
\text { parent object? }\end{array}$ & $1(0.52)$ & $\mathrm{NF}$ & $\mathrm{NF}$ \\
\hline boolean value operators & $\mathrm{I}_{\mathrm{S}}$ & $\begin{array}{l}\text { Which of the operators can } \\
\text { operate on a Boolean variable? }\end{array}$ & $3(0.57)$ & $\mathrm{NF}$ & $1(0.4)$ \\
\hline $\begin{array}{l}\text { From main call and } \\
\text { check string palindrome } \\
\text { or not }\end{array}$ & $\mathrm{I}_{\mathrm{S}}$ & $\begin{array}{l}\text { Write a method that checks if a } \\
\text { string is a palindrome. Call } \\
\text { your method from the main } \\
\text { method. }\end{array}$ & $1(0.57)$ & $\mathrm{NF}$ & $1(0.5)$ \\
\hline $\begin{array}{l}\text { methods String available } \\
\text { under Name class some. }\end{array}$ & $\mathrm{E}_{\mathrm{S}}$ & $\begin{array}{l}\text { What are the different buffer } \\
\text { string methods in java? }\end{array}$ & $1(0.62)$ & $1(0.33)$ & NF \\
\hline
\end{tabular}




\begin{tabular}{|c|c|c|c|c|c|}
\hline \multirow{2}{*}{$\begin{array}{l}\text { Buffer } \\
\text { high power file copy }\end{array}$} & & & & & \\
\hline & $\mathrm{I}_{\mathrm{S}}$ & $\begin{array}{l}\text { Which streams are advised to } \\
\text { use to have maximum } \\
\text { performance in file copying? }\end{array}$ & NF & NF & NF \\
\hline $\begin{array}{l}\text { compare different } \\
\text { controls for visibility }\end{array}$ & $\mathrm{I}_{\mathrm{S}}$ & $\begin{array}{l}\text { Explain the different visibility } \\
\text { controls and also compare with } \\
\text { each of them. }\end{array}$ & $1(0.54)$ & $1(0.51)$ & $1(0.66)$ \\
\hline $\begin{array}{l}\text { use reflection to build } \\
\text { array }\end{array}$ & $\mathrm{I}_{\mathrm{S}}$ & $\begin{array}{l}\text { How to create arrays } \\
\text { dynamically using reflection } \\
\text { package. }\end{array}$ & $1(0.59)$ & NF & NF \\
\hline $\begin{array}{l}\text { voice message with } \\
\text { playMessage method }\end{array}$ & $\mathrm{E}_{\mathrm{G}}$ & $\begin{array}{l}\text { Develop a message abstract } \\
\text { class which contains } \\
\text { playMessage abstract method. } \\
\text { Write a different sub-classes } \\
\text { like TextMessage } \\
\text { VoiceMessage and } \\
\text { FaxMessage classes for to } \\
\text { implementing the playMessage } \\
\text { method. }\end{array}$ & $\mathrm{NF}$ & $\mathrm{NF}$ & NF \\
\hline $\begin{array}{l}\text { all methods of object } \\
\text { class }\end{array}$ & $\mathrm{I}_{\mathrm{S}}$ & $\begin{array}{l}\text { Explain the different methods } \\
\text { supported in Object class with } \\
\text { example. }\end{array}$ & $2(0.53)$ & $2(0.33)$ & $2(0.42)$ \\
\hline $\begin{array}{l}\text { special style of text } \\
\text { example }\end{array}$ & $E_{G}$ & $\begin{array}{l}\text { How do achieve special fonts } \\
\text { for your text? Give example. }\end{array}$ & $1(0.64)$ & $1(0.54)$ & $1(0.42)$ \\
\hline keep integer overflow & $\mathrm{I}_{\mathrm{S}}$ & $\begin{array}{l}\text { How does Java handle integer } \\
\text { overflows and underflows? }\end{array}$ & $1(0.65)$ & $1(0.47)$ & NF \\
\hline thread start initial & $\mathrm{I}_{\mathrm{S}}$ & $\begin{array}{l}\text { When a thread is created and } \\
\text { started what is its initial state? }\end{array}$ & $1(0.56)$ & $1(0.47)$ & NF \\
\hline $\begin{array}{l}\text { shift operation in short } \\
\text { circuit }\end{array}$ & $\mathrm{E}_{\mathrm{G}}$ & $\begin{array}{l}\text { Explain short circuited } \\
\text { operators and shift operators }\end{array}$ & $1(0.59)$ & $1(0.31)$ & NF \\
\hline $\begin{array}{l}\text { what are different } \\
\text { interface implement }\end{array}$ & $\mathrm{I}_{\mathrm{S}}$ & $\begin{array}{l}\text { Describe different forms of } \\
\text { interface implementation with } \\
\text { their syntax declaration. }\end{array}$ & $\mathrm{NF}$ & NF & $\mathrm{NF}$ \\
\hline all ways to call method & $\mathrm{I}_{\mathrm{S}}$ & $\begin{array}{l}\text { What are the different ways of } \\
\text { calling a static method from a } \\
\text { program? }\end{array}$ & $1(0.52)$ & NF & NF \\
\hline $\begin{array}{l}\text { java program to create } \\
\text { person from class }\end{array}$ & $\mathrm{I}_{\mathrm{S}}$ & $\begin{array}{l}\text { Consider a class person with } \\
\text { attributes firstname and } \\
\text { lastname. Write a java program } \\
\text { to create and clone instances of } \\
\text { the Person class. }\end{array}$ & $1(0.72)$ & $\mathrm{NF}$ & $1(0.4)$ \\
\hline vector difference show & $\mathrm{E}_{\mathrm{G}}$ & $\begin{array}{l}\text { How vector is different from } \\
\text { array? Illustrate with } \\
\text { programming Example. }\end{array}$ & $2(0.68)$ & $1(0.33)$ & NF \\
\hline $\begin{array}{l}\text { break statement how } \\
\text { different }\end{array}$ & $\mathrm{E}_{\mathrm{G}}$ & $\begin{array}{l}\text { Write the difference between } \\
\text { break and continue statements }\end{array}$ & $1(0.56)$ & $1(0.4)$ & $2(0.67)$ \\
\hline
\end{tabular}




\begin{tabular}{|c|c|c|c|c|c|}
\hline & & in Java. & & & \\
\hline $\begin{array}{l}\text { more than one } \\
\text { inheritance support }\end{array}$ & $\mathrm{E}_{\mathrm{G}}$ & $\begin{array}{l}\text { What is inheritance? Is } \\
\text { multiple inheritance supported } \\
\text { by Java? }\end{array}$ & $1(0.52)$ & $1(0.31)$ & $2(0.33)$ \\
\hline $\begin{array}{l}\text { applet application } \\
\text { program }\end{array}$ & $\mathrm{I}_{\mathrm{S}}$ & $\begin{array}{l}\text { What is an applet? How do } \\
\text { applets differ from an } \\
\text { application program? }\end{array}$ & $1(0.82)$ & $\mathrm{NF}$ & $1(0.5)$ \\
\hline import class in program & $\mathrm{E}_{\mathrm{G}}$ & $\begin{array}{l}\text { How can class be imported } \\
\text { from a package to a program? }\end{array}$ & $1(0.76)$ & $\mathrm{NF}$ & $1(0.4)$ \\
\hline $\begin{array}{l}\text { can interface be used in } \\
\text { class }\end{array}$ & $\mathrm{I}_{\mathrm{S}}$ & $\begin{array}{l}\text { Is it possible to use few } \\
\text { methods of an interface in a } \\
\text { class? If so, how? }\end{array}$ & $1(0.66)$ & $\mathrm{NF}$ & $\mathrm{NF}$ \\
\hline $\begin{array}{l}\text { monitor procedure for } \\
\text { many }\end{array}$ & $\mathrm{I}_{\mathrm{S}}$ & $\begin{array}{l}\text { What is the procedure to own } \\
\text { the monitor by many threads? }\end{array}$ & $1(0.64)$ & $1(0.44)$ & $1(0.33)$ \\
\hline package import auto & $\mathrm{I}_{\mathrm{S}}$ & $\begin{array}{l}\text { Does java.lang package is } \\
\text { automatically imported into all } \\
\text { programs. }\end{array}$ & $2(0.72)$ & $1(0.47)$ & NF \\
\hline $\begin{array}{l}\text { what is architecture } \\
\text { independence }\end{array}$ & $\mathrm{I}_{\mathrm{S}}$ & $\begin{array}{l}\text { Explain architecture neutral \& } \\
\text { platform independent. }\end{array}$ & $2(0.51)$ & NF & $2(0.33)$ \\
\hline $\begin{array}{l}\text { important classpath } \\
\text { variable }\end{array}$ & $\mathrm{E}_{\mathrm{G}}$ & $\begin{array}{l}\text { Write an importance of } \\
\text { classpath variable. }\end{array}$ & $1(0.73)$ & NF & $1(0.4)$ \\
\hline $\begin{array}{l}\text { need to import lang } \\
\text { package }\end{array}$ & $\mathrm{E}_{\mathrm{G}}$ & $\begin{array}{l}\text { Do I need to import java lang } \\
\text { package any time? Why? }\end{array}$ & $1(0.81)$ & NF & $1(0.66)$ \\
\hline what is serial & $E_{G}$ & Explain serialization? & $1(0.68)$ & $\mathrm{NF}$ & $\mathrm{NF}$ \\
\hline what locale class & $\mathrm{I}_{\mathrm{S}}$ & $\begin{array}{l}\text { What is the significance of } \\
\text { Locale class? }\end{array}$ & $1(0.86)$ & NF & NF \\
\hline $\begin{array}{l}\text { what are the alternatives } \\
\text { to inheritance }\end{array}$ & $\mathrm{E}_{\mathrm{G}}$ & $\begin{array}{l}\text { Mention some alternatives to } \\
\text { inheritance. }\end{array}$ & $2(0.55)$ & NF & NF \\
\hline $\begin{array}{l}\text { is the method what } \\
\text { finalize? of use }\end{array}$ & $\mathrm{E}_{\mathrm{S}}$ & $\begin{array}{l}\text { Explain the use of finalize } \\
\text { method }\end{array}$ & $1(0.86)$ & $1(0.57)$ & $1(0.6)$ \\
\hline $\begin{array}{l}\text { each of control for what } \\
\text { the is use structure }\end{array}$ & $\mathrm{E}_{\mathrm{S}}$ & $\begin{array}{l}\text { What is the use of each control } \\
\text { structure? }\end{array}$ & $1(0.86)$ & $1(0.5)$ & $1(0.6)$ \\
\hline $\begin{array}{l}\text { any give } 4++\mathrm{C} \text { and } \\
\text { Java differences. } \\
\text { between }\end{array}$ & $\mathrm{E}_{\mathrm{S}}$ & $\begin{array}{l}\text { Give any } 4 \text { differences between } \\
\text { java and } \mathrm{C}++ \text {. }\end{array}$ & $1(0.6)$ & NF & $1(0.25)$ \\
\hline $\begin{array}{l}\text { Of what handle can the } \\
\text { are Java programs types }\end{array}$ & $\mathrm{E}_{\mathrm{S}}$ & $\begin{array}{l}\text { What are the different types of } \\
\text { program Java can handle? }\end{array}$ & NF & NF & $1(0.42)$ \\
\hline $\begin{array}{l}\text { What platform is } \\
\text { independency }\end{array}$ & $\mathrm{E}_{\mathrm{S}}$ & $\begin{array}{l}\text { What is platform } \\
\text { independency? }\end{array}$ & $1(0.81)$ & $1(0.57)$ & $1(0.5)$ \\
\hline $\begin{array}{l}\text { in of symbols comment } \\
\text { types different are java } \\
\text { What the }\end{array}$ & $\mathrm{E}_{\mathrm{S}}$ & $\begin{array}{l}\text { What are the different types of } \\
\text { comment symbols in Java }\end{array}$ & $1(0.57)$ & NF & $1(0.5)$ \\
\hline $\begin{array}{l}\text { How is a constant in } \\
\text { Java defined }\end{array}$ & $\mathrm{E}_{\mathrm{S}}$ & $\begin{array}{l}\text { How is a constant defined in } \\
\text { Java? }\end{array}$ & $1(0.81)$ & $1(0.47)$ & $1(0.4)$ \\
\hline $\begin{array}{l}\text { use keyword is the what } \\
\text { of final }\end{array}$ & $\mathrm{E}_{\mathrm{S}}$ & $\begin{array}{l}\text { What is the use of final } \\
\text { keyword? }\end{array}$ & $1(0.86)$ & $\mathrm{NF}$ & $1(0.6)$ \\
\hline
\end{tabular}




\begin{tabular}{|c|c|c|c|c|c|}
\hline $\begin{array}{l}\text { the of is control } \\
\text { structure use what each } \\
\text { for }\end{array}$ & $\mathrm{E}_{\mathrm{S}}$ & $\begin{array}{l}\text { What is the use of each control } \\
\text { structure? }\end{array}$ & $1(0.86)$ & $1(0.5)$ & $1(0.6)$ \\
\hline $\begin{array}{l}\text { constants constants } \\
\text { static and compare final }\end{array}$ & $\mathrm{E}_{\mathrm{S}}$ & $\begin{array}{l}\text { Compare static constants and } \\
\text { final constants }\end{array}$ & $1(0.53)$ & NF & $1(0.5)$ \\
\hline $\begin{array}{l}\text { need methods for is the } \\
\text { what static }\end{array}$ & $\mathrm{E}_{\mathrm{S}}$ & $\begin{array}{l}\text { What is the need for static } \\
\text { method? }\end{array}$ & $1(0.72)$ & $1(0.37)$ & $1(0.6)$ \\
\hline $\begin{array}{l}\text { platform supports how } \\
\text { java independency }\end{array}$ & $\mathrm{E}_{\mathrm{S}}$ & $\begin{array}{l}\text { How java supports platform } \\
\text { independency? }\end{array}$ & $1(0.72)$ & $1(0.51)$ & $1(0.5)$ \\
\hline $\begin{array}{l}\text { to important java why is } \\
\text { internet }\end{array}$ & $\mathrm{E}_{\mathrm{S}}$ & $\begin{array}{l}\text { Why java is important to the } \\
\text { internet? }\end{array}$ & $1(0.54)$ & NF & $1(0.16)$ \\
\hline $\begin{array}{l}\text { is internet to java } \\
\text { important why }\end{array}$ & $\mathrm{E}_{\mathrm{S}}$ & $\begin{array}{l}\text { Why java is important to the } \\
\text { internet? }\end{array}$ & $1(0.57)$ & NF & $1(0.16)$ \\
\hline $\begin{array}{l}\text { Application and Applet } \\
\text { Compare }\end{array}$ & $\mathrm{E}_{\mathrm{S}}$ & $\begin{array}{l}\text { Compare applet and } \\
\text { application }\end{array}$ & NF & NF & NF \\
\hline $\begin{array}{l}\text { difference copy with } \\
\text { clone }\end{array}$ & $\mathrm{E}_{\mathrm{G}}$ & $\begin{array}{l}\text { Differentiate cloning and } \\
\text { copying. }\end{array}$ & $2(0.59)$ & $1(0.35)$ & NF \\
\hline $\begin{array}{l}\text { pros and cons of static } \\
\text { nested class }\end{array}$ & $\mathrm{E}_{\mathrm{G}}$ & $\begin{array}{l}\text { Write the advantages and } \\
\text { disadvantages of static nested } \\
\text { class. }\end{array}$ & $1(0.64)$ & $2(0.32)$ & $1(0.37)$ \\
\hline what fields method & $\mathrm{E}_{\mathrm{G}}$ & $\begin{array}{l}\text { Explain about Final class } \\
\text { Fields Methods. }\end{array}$ & NF & NF & NF \\
\hline package access specifier & $\mathrm{E}_{\mathrm{G}}$ & $\begin{array}{l}\text { What do you understand by } \\
\text { package access specifier? }\end{array}$ & $1(0.63)$ & $1(0.51)$ & $1(0.33)$ \\
\hline $\begin{array}{l}\text { priority in garbage } \\
\text { collector }\end{array}$ & $\mathrm{I}_{\mathrm{S}}$ & $\begin{array}{l}\text { Garbage collector thread } \\
\text { belongs to which priority? }\end{array}$ & $1(0.73)$ & $1(0.67)$ & $1(0.6)$ \\
\hline $\begin{array}{l}\text { circle filled when right } \\
\text { click }\end{array}$ & $\mathrm{I}_{\mathrm{S}}$ & $\begin{array}{l}\text { Develop java program that } \\
\text { changes the color of a filled } \\
\text { circle when you make a right } \\
\text { click. }\end{array}$ & $1(0.64)$ & $1(0.56)$ & $1(0.2)$ \\
\hline explain assertion use & $\mathrm{I}_{\mathrm{S}}$ & $\begin{array}{l}\text { What is an assertion? What is } \\
\text { its use in programming? }\end{array}$ & NF & NF & NF \\
\hline array fill & $\mathrm{I}_{\mathrm{S}}$ & $\begin{array}{l}\text { Give the syntax for array fill } \\
\text { operation. }\end{array}$ & $1(0.63)$ & NF & $1(0.4)$ \\
\hline method to demon thread & $\mathrm{I}_{\mathrm{S}}$ & $\begin{array}{l}\text { Which method is used to create } \\
\text { the demon thread? }\end{array}$ & $1(0.51)$ & $\mathrm{NF}$ & NF \\
\hline $\begin{array}{l}\text { what class on read side } \\
\text { byte stream }\end{array}$ & $\mathrm{E}_{\mathrm{G}}$ & $\begin{array}{l}\text { Name The Filter Stream } \\
\text { Classes On Reading Side Of } \\
\text { Byte Stream? }\end{array}$ & $1(0.71)$ & NF & NF \\
\hline $\begin{array}{l}\text { what is the use of input } \\
\text { stream }\end{array}$ & $\mathrm{E}_{\mathrm{G}}$ & $\begin{array}{l}\text { What Is The Functionality Of } \\
\text { Sequence Input Stream? }\end{array}$ & $1(0.63)$ & NF & NF \\
\hline $\begin{array}{l}\text { see if file is hidden or } \\
\text { not }\end{array}$ & $\mathrm{E}_{\mathrm{G}}$ & $\begin{array}{l}\text { How to check if a file is } \\
\text { hidden? }\end{array}$ & $1(0.81)$ & $1(0.43)$ & $1(0.5)$ \\
\hline $\begin{array}{l}\text { when was the file last } \\
\text { modified }\end{array}$ & $\mathrm{E}_{\mathrm{G}}$ & $\begin{array}{l}\text { How to get file last modified } \\
\text { time? }\end{array}$ & $1(0.7)$ & $1(0.5)$ & $1(0.42)$ \\
\hline use of encapsulation & $E_{G}$ & What is the primary benefit of & $\mathrm{NF}$ & $\mathrm{NF}$ & $\mathrm{NF}$ \\
\hline
\end{tabular}




\begin{tabular}{|c|c|c|c|c|c|}
\hline & & encapsulation? & & & \\
\hline $\begin{array}{l}\text { most used algorithm in } \\
\text { collection }\end{array}$ & $\mathrm{I}_{\mathrm{S}}$ & $\begin{array}{l}\text { What are common algorithms } \\
\text { implemented in Collections } \\
\text { Framework? }\end{array}$ & $1(0.57)$ & $1(0.36)$ & $\mathrm{NF}$ \\
\hline how is iterator designed & $\mathrm{E}_{\mathrm{G}}$ & $\begin{array}{l}\text { What is the design pattern that } \\
\text { iterator uses? }\end{array}$ & NF & NF & NF \\
\hline $\begin{array}{l}\text { component size } \\
\text { preferred }\end{array}$ & $\mathrm{I}_{\mathrm{S}}$ & $\begin{array}{l}\text { What is the preferred size of a } \\
\text { component? }\end{array}$ & $1(0.86)$ & $1(0.86)$ & $1(0.75)$ \\
\hline read each line of file & $\mathrm{E}_{\mathrm{G}}$ & $\begin{array}{l}\text { How to read file content line } \\
\text { by line in java? }\end{array}$ & $1(0.81)$ & $1(0.63)$ & $\mathrm{NF}$ \\
\hline $\begin{array}{l}\text { delete a file that is } \\
\text { temporary }\end{array}$ & $\mathrm{E}_{\mathrm{G}}$ & $\begin{array}{l}\text { How to delete temporary file in } \\
\text { java? }\end{array}$ & $1(0.86)$ & $1(0.61)$ & NF \\
\hline $\begin{array}{l}\text { calculate factorial of a } \\
\text { number }\end{array}$ & $\mathrm{I}_{\mathrm{S}}$ & $\begin{array}{l}\text { Java program to find factorial } \\
\text { of a number using loops }\end{array}$ & $1(0.51)$ & $1(0.33)$ & $1(0.25)$ \\
\hline thread priorities & $\mathrm{I}_{\mathrm{S}}$ & $\begin{array}{l}\text { Discuss about thread groups } \\
\text { and thread priorities. }\end{array}$ & $1(0.75)$ & NF & NF \\
\hline java programming & $\mathrm{I}_{\mathrm{S}}$ & $\begin{array}{l}\text { Explain Java programming } \\
\text { Environment. }\end{array}$ & $1(0.5)$ & $\mathrm{NF}$ & NF \\
\hline what are lexical issues & $\mathrm{E}_{\mathrm{G}}$ & $\begin{array}{l}\text { Discuss the lexical issues of } \\
\text { Java. }\end{array}$ & $\mathrm{NF}$ & $\mathrm{NF}$ & $\mathrm{NF}$ \\
\hline $\begin{array}{l}\text { data type used for } \\
\text { arithmeic operators }\end{array}$ & $\mathrm{E}_{\mathrm{G}}$ & $\begin{array}{l}\text { Which data type can be } \\
\text { operands of arithmetic } \\
\text { operators? }\end{array}$ & NF & $1(0.36)$ & NF \\
\hline compound assign & $\mathrm{I}_{\mathrm{S}}$ & $\begin{array}{l}\text { What are compound } \\
\text { assignment operators? }\end{array}$ & $1(0.56)$ & $1(0.4)$ & $1(0.25)$ \\
\hline use bitwise in boolean & $\mathrm{E}_{\mathrm{G}}$ & $\begin{array}{l}\text { Can bitwise operators be used } \\
\text { in Boolean operations? }\end{array}$ & $1(0.66)$ & $1(0.44)$ & NF \\
\hline order for call awt & $\mathrm{E}_{\mathrm{G}}$ & $\begin{array}{l}\text { What is the sequence for } \\
\text { calling the methods by AWT } \\
\text { for applets? }\end{array}$ & NF & NF & NF \\
\hline cast object explain & $\mathrm{E}_{\mathrm{G}}$ & $\begin{array}{l}\text { What do you understand } \\
\text { by casting an object? Explain } \\
\text { with the example }\end{array}$ & $1(0.72)$ & NF & NF \\
\hline find size of object & $\mathrm{I}_{\mathrm{S}}$ & $\begin{array}{l}\text { Does Java provide any } \\
\text { construct to find out the size of } \\
\text { an object? }\end{array}$ & $1(0.7)$ & NF & NF \\
\hline $\begin{array}{l}\text { required for try to } \\
\text { follow catch }\end{array}$ & $\mathrm{E}_{\mathrm{G}}$ & $\begin{array}{l}\text { Is it necessary that each try } \\
\text { block be followed by a catch } \\
\text { block? }\end{array}$ & $1(0.52)$ & $1(0.42)$ & $1(0.33)$ \\
\hline what is precedence rule & $\mathrm{I}_{\mathrm{S}}$ & $\begin{array}{l}\text { Explain precedence rules and } \\
\text { associativity concept }\end{array}$ & $1(0.58)$ & $\mathrm{NF}$ & NF \\
\hline $\begin{array}{l}\text { type upgrade in method } \\
\text { overloading }\end{array}$ & $\mathrm{E}_{\mathrm{G}}$ & $\begin{array}{l}\text { What type promotion has to do } \\
\text { with method overloading? }\end{array}$ & NF & NF & NF \\
\hline $\begin{array}{l}\text { explain two types of } \\
\text { polymorphism }\end{array}$ & $\mathrm{I}_{\mathrm{S}}$ & $\begin{array}{l}\text { What is run time } \\
\text { polymorphism and compile } \\
\text { time polymorphism? }\end{array}$ & $1(0.57)$ & NF & $\mathrm{NF}$ \\
\hline
\end{tabular}




\begin{tabular}{|l|c|l|c|c|c|}
\hline explain blockingqueue & $\mathrm{E}_{\mathrm{G}}$ & $\begin{array}{l}\text { What do you understand by } \\
\text { BlockingQueue? }\end{array}$ & $1(0.64)$ & $\mathrm{NF}$ & $\mathrm{NF}$ \\
\hline java and internet & $\mathrm{I}_{\mathrm{S}}$ & $\begin{array}{l}\text { Why java is important to the } \\
\text { internet }\end{array}$ & $1(0.81)$ & $1(0.66)$ & $1(0.66)$ \\
\hline \multicolumn{2}{|l|}{$\mathrm{I}_{\mathrm{S}}$ : Insufficient information } & $\mathrm{E}_{\mathrm{G}}$ : Grammatical error $\mathrm{E}_{\mathrm{S}}$ : Sequential error $\quad \mathrm{NF}$ : Not found \\
\hline
\end{tabular}




\section{Table 9 (on next page)}

Suggested similar questions from $\square$ rst iteration (pass 1) 


\begin{tabular}{|c|l|}
\hline Pass & \multicolumn{1}{c|}{ Suggested similar question } \\
\hline & - Explain garbage collection \\
& - How we can create java classes \\
Pass 1 & - How we can create java objects \\
& - Explain garbage collection in java programming \\
& - What is garbage collection \\
& - How to create a file in Java \\
& - How to read a file in Java
\end{tabular}

1 


\section{Table $\mathbf{1 0}$ (on next page)}

Diversity and evenness measures from pass 1 


\begin{tabular}{|c|c|c|c|c|c|c|c|c|c|c|c|c|c|c|c|}
\hline & 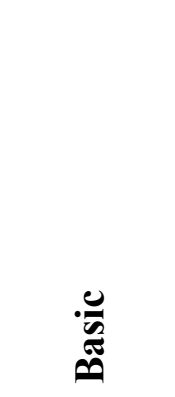 & 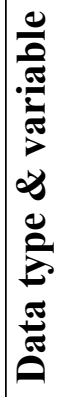 & 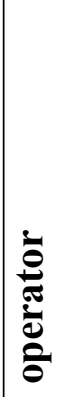 & 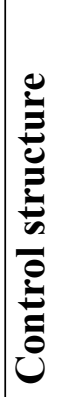 & 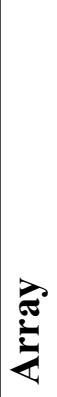 & 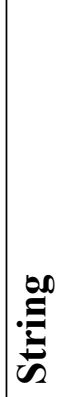 & 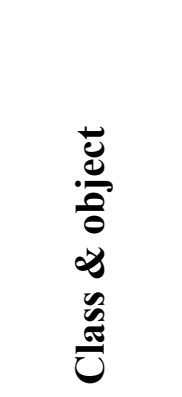 & & 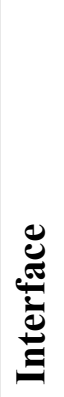 & 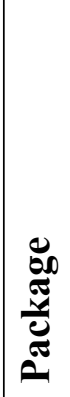 & 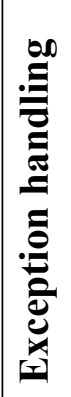 & 疍 & $\frac{\frac{\pi}{0}}{\frac{2}{2}}$ & $\stackrel{0}{\underline{1}}$ & 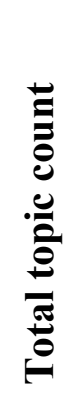 \\
\hline $\mathrm{x}$ & 5 & 0 & 0 & 0 & 0 & 0 & 5 & 0 & 0 & 0 & 0 & 0 & 0 & 2 & 12 \\
\hline $\mathrm{p}(\mathrm{x})$ & 0.416667 & 0 & 0 & 0 & 0 & 0 & 0.416667 & 0 & 0 & 0 & 0 & 0 & 0 & 0.166667 & \\
\hline $\ln (\mathrm{p}(\mathrm{x}))$ & -0.87547 & 0 & 0 & 0 & 0 & 0 & -0.87547 & 0 & 0 & 0 & 0 & 0 & 0 & -1.79176 & \\
\hline $\mathrm{p}(\mathrm{x}) \cdot \ln ((\mathrm{px}))$ & -0.36478 & 0 & 0 & 0 & 0 & 0 & -0.36478 & 0 & 0 & 0 & 0 & 0 & 0 & -0.29863 & \\
\hline Diversity & \multicolumn{15}{|l|}{1.028184} \\
\hline Evenness & 0.935893 & & & & & & & & & & & & & & \\
\hline
\end{tabular}




\section{Table 11 (on next page)}

Suggested similar questions from $\square$ rst iteration (pass 2) 


\begin{tabular}{|c|l|}
\hline Pass & \multicolumn{1}{c|}{ Suggested similar question } \\
\hline & - What is garbage collection? \\
& - Explain java data types? \\
- Explain garbage collection. \\
Pass 2 & - Explain garbage collection in java programming. \\
& - What is the purpose of garbage collection in Java? When is it used? \\
& - Explain finalize and garbage collection in Java \\
& - How are objects released in garbage collection?
\end{tabular}

1 


\section{Table 12 (on next page)}

Diversity and evenness measures from pass 2 


\begin{tabular}{|c|c|c|c|c|c|c|c|c|c|c|c|c|c|c|c|}
\hline & 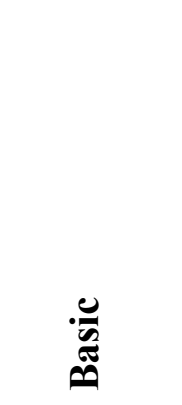 & 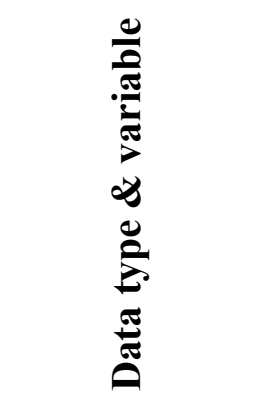 & 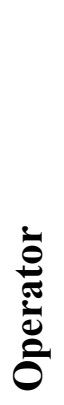 & 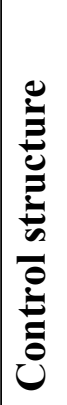 & 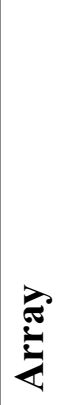 & 占 & 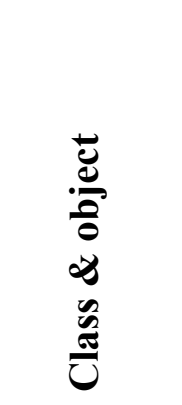 & 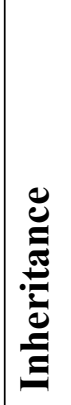 & & 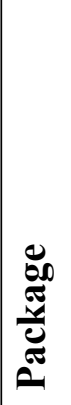 & 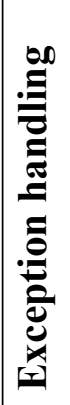 & 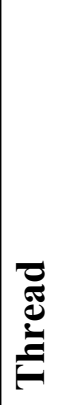 & $\frac{\pi}{\frac{\pi}{2}}$ & $\stackrel{?}{\underline{2}}$ & $\stackrel{\text { శ్ }}{0}$ \\
\hline $\mathrm{X}$ & 4 & 1 & 0 & 0 & 0 & 0 & 8 & 0 & 0 & 0 & 0 & 0 & 0 & 0 & 13 \\
\hline$p(x)$ & 0.307692 & 0.076923077 & 0 & 0 & 0 & 0 & 0.615385 & 0 & 0 & 0 & 0 & 0 & 0 & 0 & \\
\hline $\ln (\mathrm{p}(\mathrm{x}))$ & -1.17865 & -2.564949357 & 0 & 0 & 0 & 0 & -0.48551 & 0 & 0 & 0 & 0 & 0 & 0 & 0 & \\
\hline $\mathrm{p}(\mathrm{x}) \cdot \ln ((\mathrm{px}))$ & -0.36266 & -0.197303797 & 0 & 0 & 0 & 0 & -0.29877 & 0 & 0 & 0 & 0 & 0 & 0 & 0 & \\
\hline Diversity & \multicolumn{15}{|l|}{0.858741} \\
\hline Evenness & \multicolumn{15}{|l|}{0.78166} \\
\hline
\end{tabular}




\section{Table $\mathbf{1 3}$ (on next page)}

Diversity index and equitability on recommended questions 


\begin{tabular}{|c|c|c|c|c|c|c|c|c|c|c|c|c|}
\hline & \multicolumn{4}{|c|}{ Soft cosine } & \multicolumn{4}{|c|}{ Cosine } & \multicolumn{4}{|c|}{ Jaccard } \\
\hline & \multicolumn{2}{|c|}{ Pass 1} & \multicolumn{2}{|c|}{ Pass 2} & \multicolumn{2}{|c|}{ Pass 1} & \multicolumn{2}{|c|}{ Pass 2} & \multicolumn{2}{|c|}{ Pass 1} & \multicolumn{2}{|c|}{ Pass 2} \\
\hline & 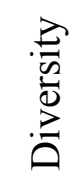 & 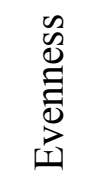 & 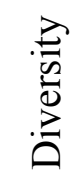 & 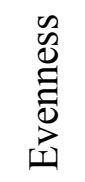 & 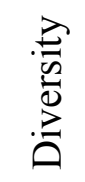 & $\underset{\substack{0 \\
0}}{\stackrel{D}{0}}$ & 衤 & 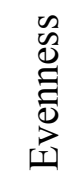 & 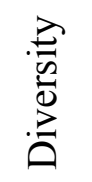 & 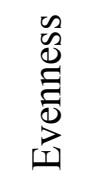 & 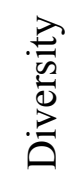 & 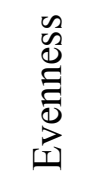 \\
\hline $\begin{array}{l}\text { java not have } \\
\text { destroy and how } \\
\text { garbage collect }\end{array}$ & 1.02 & 0.93 & 0.85 & 0.78 & 0 & 0 & 1.72 & 0.96 & 0 & 0 & 0.41 & 0.37 \\
\hline how to overload & 0.67 & 0.97 & 0.50 & 0.72 & 0 & 0 & 1.03 & 0.94 & 0 & 0 & 0.79 & 0.72 \\
\hline $\begin{array}{l}\text { why thread } \\
\text { synchronization } \\
\text { needed }\end{array}$ & 0.45 & 0.41 & 0 & 0 & 0.32 & 0.46 & 0.60 & 0.54 & 0 & 0 & 1.69 & 0.94 \\
\hline $\begin{array}{l}\text { we change throws } \\
\text { when override }\end{array}$ & 0.63 & 0.91 & 0 & 0 & 0.79 & 0.72 & 0 & 0 & 0.94 & 0.85 & 0.50 & 0.72 \\
\hline $\begin{array}{l}\text { all methods of } \\
\text { object class }\end{array}$ & 1.19 & 0.86 & 1.08 & 0.78 & 1.16 & 0.84 & 1.27 & 0.92 & 0.75 & 0.69 & 0.85 & 0.78 \\
\hline $\begin{array}{l}\text { vector difference } \\
\text { show }\end{array}$ & 0.56 & 0.51 & 0.63 & 0.91 & 1.58 & 0.88 & NA & NA & 0.50 & 0.72 & 1.88 & 0.96 \\
\hline $\begin{array}{l}\text { package import } \\
\text { auto }\end{array}$ & 0.41 & 0.59 & 0 & 0 & 0 & 0 & NA & NA & 0 & 0 & 0.90 & 0.81 \\
\hline $\begin{array}{l}\text { what is } \\
\text { architecture } \\
\text { independence }\end{array}$ & 1.27 & 0.71 & 0 & 0 & 1.60 & 0.89 & 1.60 & 0.89 & 0 & 0 & 0 & 0 \\
\hline Why main public & 0 & 0 & 0 & 0 & 0.50 & 0.72 & 1.24 & 0.89 & 0 & 0 & 0.45 & 0.65 \\
\hline
\end{tabular}

